\title{
NEET In-Pile Ultrasonic Sensor Enablement-FY-2013 Status Report
}

\author{
J. Daw, J. Rempe, J. Palmer (INL) \\ P. Ramuhalli, R. Montgomery (PNNL) \\ H.T. Chien (ANL) \\ B. Tittmann, B. Reinhardt (PSU) \\ G. Kohse (MIT)
}

September 2013

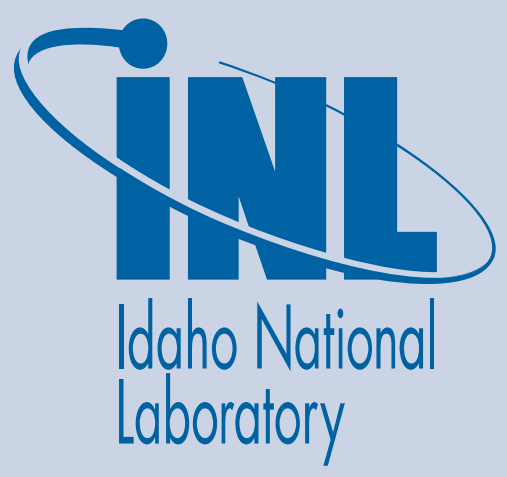

The INL is a U.S. Department of Energy National Laboratory operated by Battelle Energy Alliance 


\section{DISCLAIMER}

This information was prepared as an account of work sponsored by an agency of the U.S. Government. Neither the U.S. Government nor any agency thereof, nor any of their employees, makes any warranty, expressed or implied, or assumes any legal liability or responsibility for the accuracy, completeness, or usefulness, of any information, apparatus, product, or process disclosed, or represents that its use would not infringe privately owned rights. References herein to any specific commercial product, process, or service by trade name, trade mark, manufacturer, or otherwise, does not necessarily constitute or imply its endorsement, recommendation, or favoring by the U.S. Government or any agency thereof. The views and opinions of authors expressed herein do not necessarily state or reflect those of the U.S. Government or any agency thereof. 
INL/EXT-13-29144

\title{
NEET In-Pile Ultrasonic Sensor Enablement-FY-2013 Status Report
}

\author{
J. Daw \\ J. Rempe \\ J. Palmer \\ P. Ramuhalli R. \\ Montgomery \\ HT Chien \\ B. Tittmann B. \\ Reinhardt G. \\ Kohse \\ September 2013 \\ Idaho National Laboratory \\ Idaho Falls, Idaho 83415 \\ Prepared for the \\ U.S. Department of Energy \\ Office of Nuclear Energy \\ Under DOE Idaho Operations Office \\ Contract DE-AC07-05ID14517
}


This page intentionally left blank. 


\section{SUMMARY}

Several programs funded by the Department of Energy Office of Nuclear Energy (DOE-NE), such as the Fuel Cycle Research and Development, Advanced Reactor Concepts, Light Water Reactor Sustainability, and Next Generation Nuclear Plant programs, are investigating new fuels and materials for advanced and existing reactors. A key objective of such programs is to understand the performance of these fuels and materials when irradiated. The Nuclear Energy Enabling Technology (NEET) Advanced Sensors and Instrumentation (ASI) in-pile instrumentation development activities are focused upon addressing cross-cutting needs for DOE-NE irradiation testing by providing higher fidelity, real-time data, with increased accuracy and resolution from smaller, compact sensors that are less intrusive.

Ultrasonic technologies offer the potential to measure a range of parameters, including geometry changes, temperature, crack initiation and growth, gas pressure and composition, and microstructural changes under harsh irradiation test conditions. There are two primary issues that currently limit in-pile deployment of ultrasonic sensors. The first is transducer survivability. The ability of ultrasonic transducer materials to maintain their useful properties during an irradiation must be demonstrated. The second issue is signal processing. Ultrasonic testing is typically performed in a lab or field environment, where the sensor and sample are accessible. The harsh nature of in-pile testing and the variety of measurements that are desired demand that an enhanced signal processing capability be developed to make in-pile ultrasonic sensors viable. To address these issues, the NEET ASI program is funding the Ultrasonic Transducer Irradiation and Signal Processing Enhancements project, which is a collaborative effort between the Idaho National Laboratory, the Pacific Northwest National Laboratory, the Argonne National Laboratory, and the Pennsylvania State University (PSU). As summarized within this document, significant work has been accomplished during the first two years of this three year project:

- Transducer Irradiation Test - The first task of this project supports efforts to develop a test capsule design and define irradiation conditions for evaluating most promising candidate piezoelectric and magnetostrictive transducer materials and designs. In July FY-2012, the ATR NSUF announced that a proposal led by PSU for irradiating ultrasonic transducers was selected, and the irradiation would occur in the Massachusetts Institute of Technology Nuclear Research Reactor (MITR). Subsequent project efforts have focused on developing a capsule design and on identifying appropriate test conditions, identifying transducers for inclusion in the capsule, appropriate post-irradiation examinations, and performing out-of-pile laboratory tests needed to support the irradiation. As documented in this report, the irradiation test builds on prior research and exceeds previous tests in terms of the number of materials tested and accumulated fluence. The purpose of this test is to irradiate the most promising transducer materials to a total fast fluence of at least $1 \times 10^{21} \mathrm{n} / \mathrm{cm}^{2}$. Four piezoelectric transducers and two magnetostrictive transducers will be included in this irradiation test, and additional loose 'tuck in' samples of candidate piezoelectric and magnetostrictive transducer materials will be included for post-irradiation examinations. This project selected suitable piezoelectric and magnetostrictive candidates on the basis of material properties and previous research. Piezoelectric materials identified for inclusion are aluminum nitride $(\mathrm{AlN})$, bismuth titanate $\left(\mathrm{Bi}_{4} \mathrm{~T}_{3} \mathrm{iO}_{12}\right)$, and zinc oxide ( $\mathrm{ZnO})$. Magnetostrictive materials proposed for inclusion are Remendur and Galfenol. During FY-2013, transducer design issues, such as electrical connections and transducer to sample coupling, were addressed. An updated test capsule design was developed that is capable of accommodating all test specimens as well as real time instrumentation for monitoring temperature and neutron and gamma flux.

- Signal Processing Enhancement - The second task of this project addresses the need for an enhanced signal processing capability for future in-pile ultrasonic measurements. In order to accommodate the support required for the irradiation test in FY-2013, the workscope for this task has been deferred 
until FY-2014. However, a detailed workscope has been developed, and the plan is to complete Task 2 activities for this project by the third quarter of FY-2014.

In summary, two issues related to the future deployment of ultrasonic sensors in irradiation tests are being addressed by the current project. As documented in this report, this three year project has completed all planned accomplishments for the first two years, and it is anticipated that the test capsule will be inserted into the MITR in early FY-2014. 


\section{CONTENTS}

SUMMARY iii

FIGURES vii

TABLES ix

ACRONYMS xi

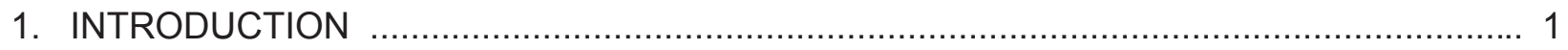

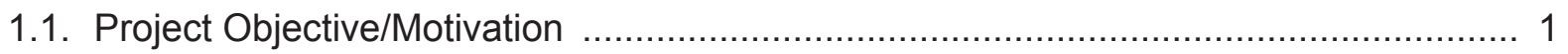

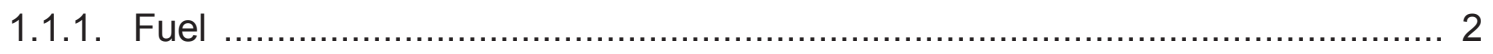

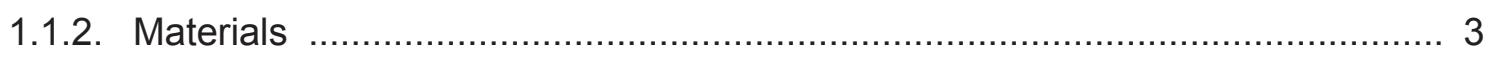

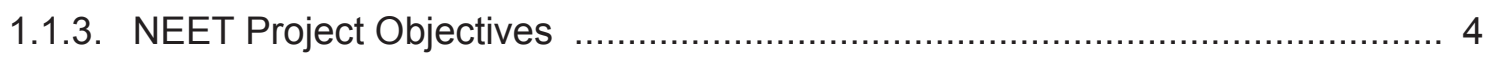

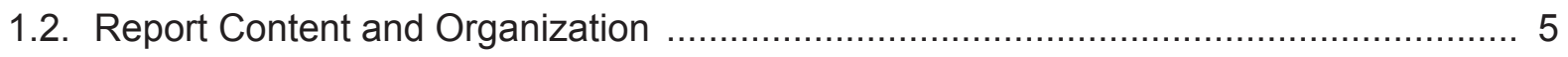

2. TASK 1: ULTRASONIC TRANSDUCER IRRADIATION TEST ..................................... 7

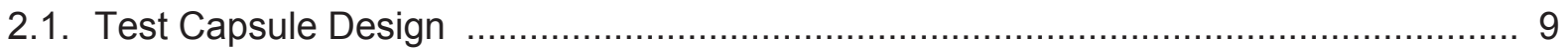

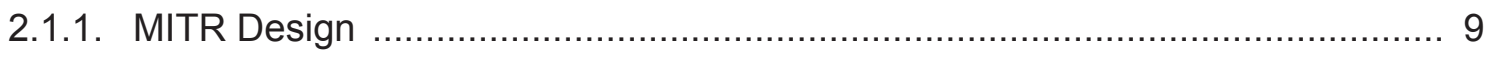

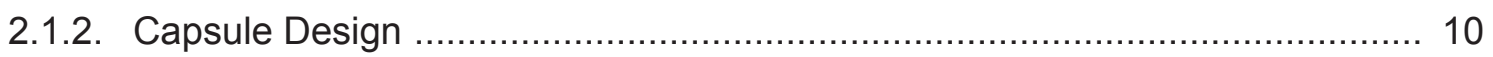

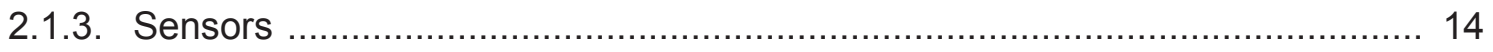

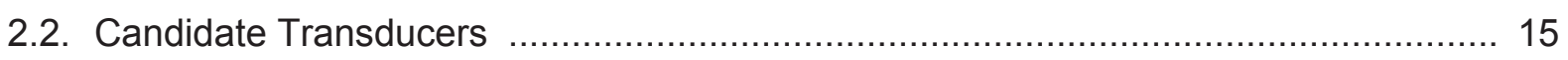

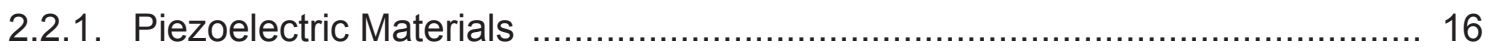

2.2.2. Piezoelectric Transducers ............................................................... 17

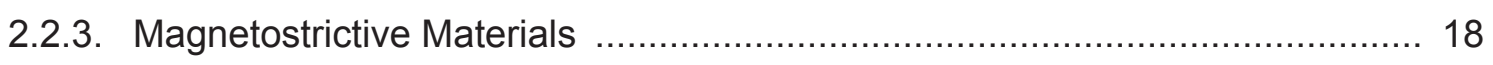

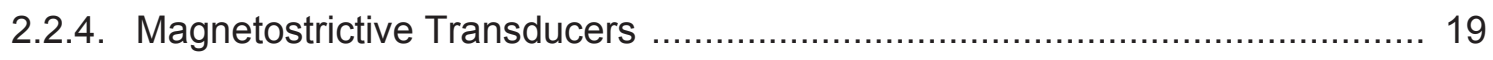

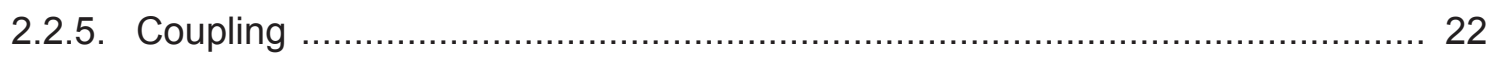

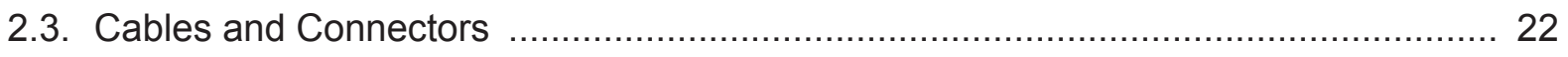

2.3.1. In-Core Cables and Connectors ..................................................... 24

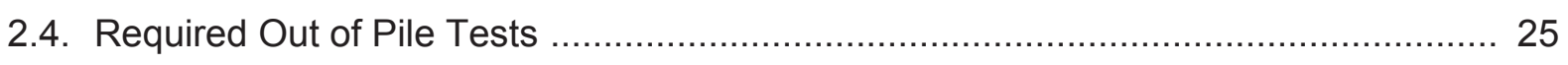

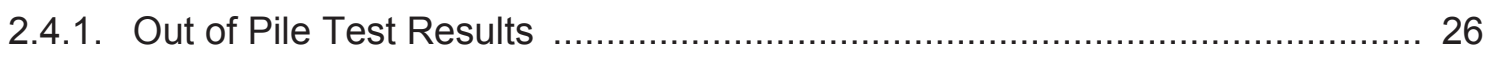

2.4.1.1. Performance Check Out Tests .......................................... 26

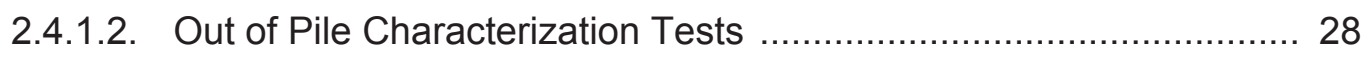

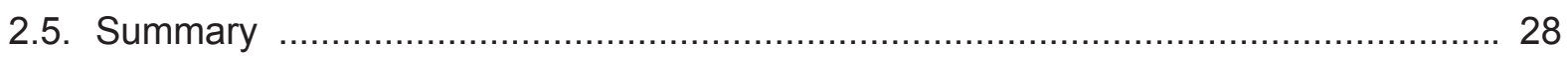

3. TASK 2: ULTRASONIC SIGNAL PROCESSING METHODS ................................... 29

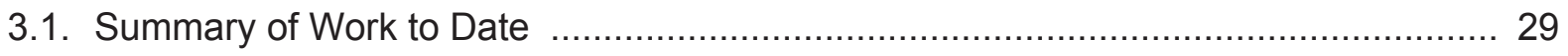

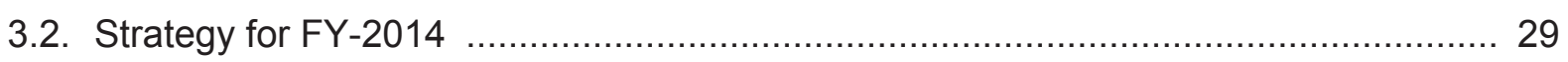

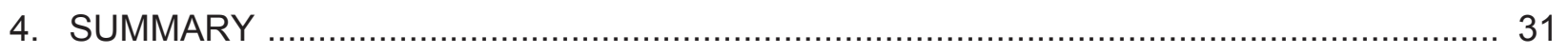

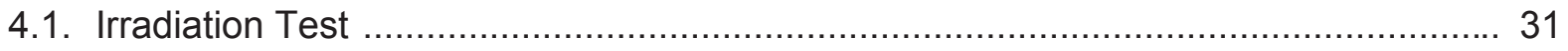

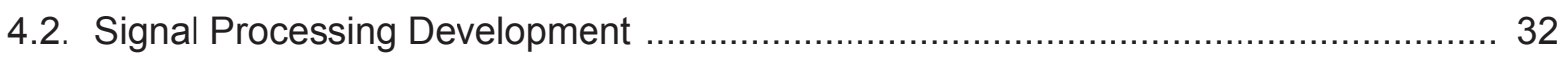

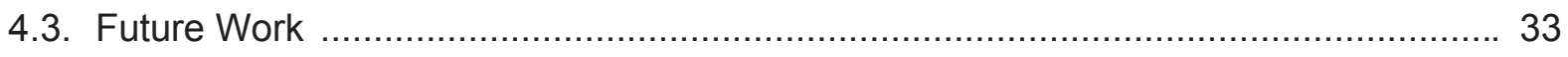


NEET In-Pile Ultrasonic Sensor Enablement-FY 2013 Status Report

September 2013

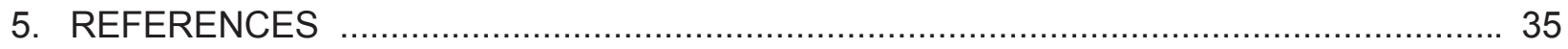




\section{FIGURES}

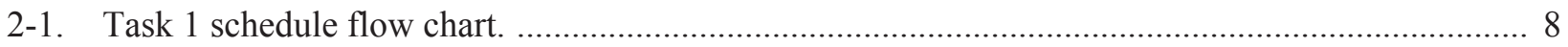

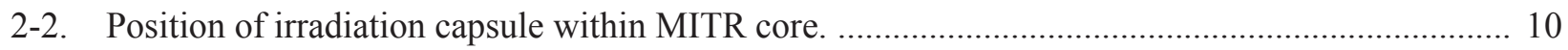

2-3. Initial test capsule graphite sample holder design with sample and instrumentation positions

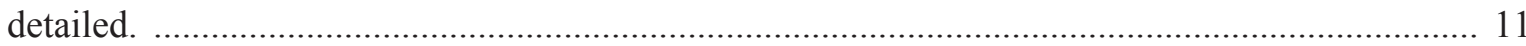

2-4. Calculated temperature distribution within graphite sample holder. Temperatures are in degrees Celsius.

2-5. Calculated surface temperature distribution for test transducers. Temperatures are in degrees Celsius.

2-6. Final test capsule graphite sample holder design with sample and instrumentation positions detailed.

2-7. Results of thermal analysis of redesigned test capsule predicting lower transducer surface temperatures. Temperatures are in degrees Celsius. ............................................................... 14

2-8. Schematic diagram of SPND and SPGD (dimensions are the same for each). ......................... 15

2-9. Example melt wire capsule with five wire types. ..................................................................... 15

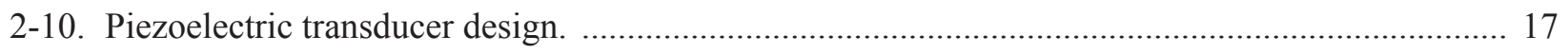

2-11. Two piezoelectric transducers laid out prior to assembly. ........................................................ 18

2-12. $\mathrm{ZnO}$ piezoelectric chip prior to incorporation into transducer. .................................................. 18

2-13. Piezoelectric transducer (a) Original transducer with alumina bead connection to extension cable. (b) Enhanced transducer with strain relief sleeve designed to support connection to cable.

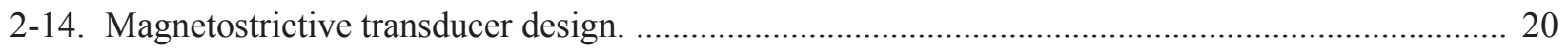

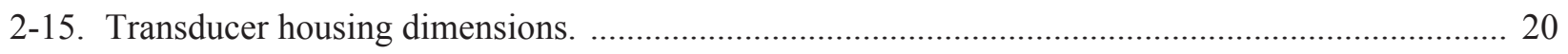

2-16. Steps involved in making high temperature capable magnetostrictive transducer. ...................... 21

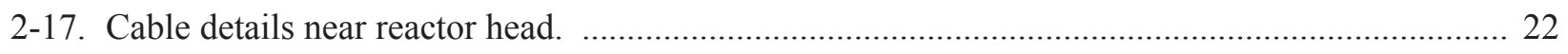

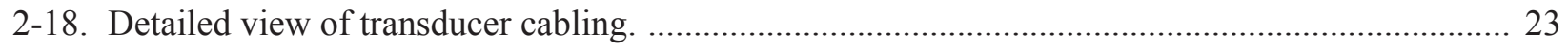

2-20. Setup used for initial magnetostrictive transducer checkout. ..................................................... 27

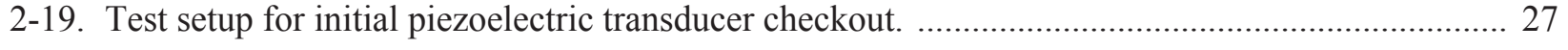

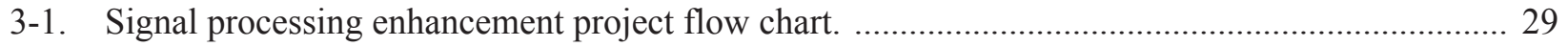

4-1. Final test capsule graphite sample holder design with sample and instrumentation positions detailed. 
NEET In-Pile Ultrasonic Sensor Enablement-FY 2013 Status Report

September 2013 


\section{TABLES}

Table 1-1.Summary of desired parameters for detection during fuel irradiation tests. .............................. 2

Table 1-2.Summary of desired parameters for detection during materials irradiation tests.' ....................... 4

Table 2-1.Representative dimensions and flux levels in MITR. ......................................................... 9

Table 2-2.Compositions and melting temperatures of melt wires........................................................... 15

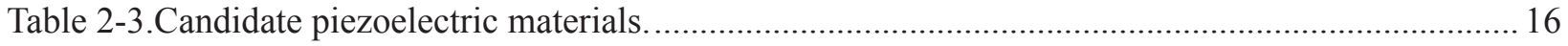

Table 2-4.Candidate magnetostrictive materials................................................................................. 19

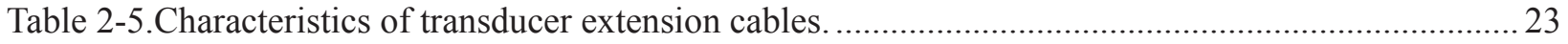

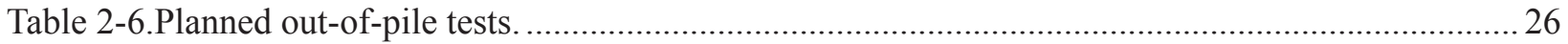

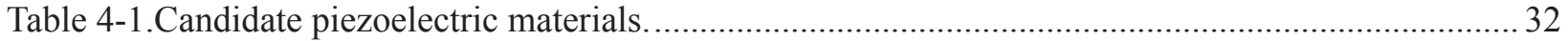

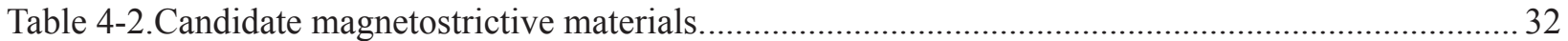


NEET In-Pile Ultrasonic Sensor Enablement-FY 2013 Status Report

September 2013 


\section{ACRONYMS}

ANL Argonne National Laboratory

ARC Advanced Reactor Concepts

ASI Advanced Sensors and Instrumentation

ATR Advanced Test Reactor

BNC Baynet Neill-Concelman

BWR Boiling Water Reactor

DOE Department of Energy

DOE-NE Office of Nuclear Energy in the Department of Energy

DSC Differential Scanning Calorimeter

ENDF Evaluated Nuclear Data Files

FCRD Fuel Cycle Research and Development

HTGR High Temperature Gas Reactor

HTTL High Temperature Test Laboratory

ID Inner Diameter

INL Idaho National Laboratory

LWR Light Water Reactor

MI Mineral Insulated

MIT Massachusetts Institute of Technology

MITR Massachusetts Institute of Technology Nuclear Research Reactor

NEET Nuclear Energy Enabling Technologies

NDE Nondestructive Evaluation

NGNP Next Generation Nuclear Plant

NDT Nondestructive Testing

NSUF National Scientific User Facility

OD Outer Diameter

PIE Post-Irradiation Examination

PNNL Pacific Northwest National Laboratory

PSU The Pennsylvania State University

PWR Pressurized Water Reactor

PZT Lead Zirconium Titanate

SFR Sodium Fast Reactor

SMR Small Modular Reactor

SNR Signal to Noise Ratio

SPGD Self Powered Gamma Detector

SPND Self Powered Neutron Detector

TRIGA Training, Research, Isotopes, General Atomics

TRISO Tri-Structural Isotropic

UT Ultrasonic Thermometer 
NEET In-Pile Ultrasonic Sensor Enablement-FY 2013 Status Report

September 2013 


\section{INTRODUCTION}

Ultrasonic technologies offer the potential to measure a range of parameters, including geometry changes, temperature, crack initiation and growth, gas pressure and composition, and microstructural changes, under harsh irradiation test conditions. Many Department of Energy-Office of Nuclear Energy (DOE-NE) programs (e.g., Light Water Reactor Sustainability (LWRS), Fuel Cycle Research and Development (FCRD), Advanced Test Reactor National Scientific User Facility (ATR NSUF), Advanced Reator Concepts (ARC), Small Modular Reactors (SMRs), Next Generation Nuclear Plant (NGNP), etc.) would benefit from the use of ultrasonic technologies to provide enhanced sensors for in-pile instrumentation during irradiation testing. For example, FCRD efforts are evaluating the ability of single, small diameter ultrasonic thermometers (UTs) to provide a temperature profile in candidate metallic and oxide fuel. Other ultrasonic methods may be evaluated in future work. ${ }^{1}$

It is recognized that measurement accuracies may be considerably enhanced, and the potential exists for significant reductions in irradiation capsule size, if ultrasonic transducers can be deployed in-pile. It is currently anticipated that some of the applications under investigation require high frequency piezoelectric transducers, which have previously been observed to suffer rapid degradation when exposed to neutron radiation. Another technology deployment issue common to many ultrasonic measurement techniques is the need for enhanced signal processing techniques, as the in-core environment is known to cause significant signal noise. This project addresses both technology deployment issues that are common to various types of ultrasonic measurements.

\subsection{Project Objective/Motivation}

Several DOE-NE programs, such as the FCRD, ${ }^{2}$ ARC, ${ }^{3,4}$ LWRS, $^{5}$ and NGNP $6-12$ programs, are investigating new fuels and materials for advanced and existing reactors. A key objective of such programs is to understand the performance of these fuels and materials during irradiation. The Nuclear Energy Enabling Technology (NEET) Advanced Sensors and Instrumentation (ASI) in-pile instrumentation development activities are focused upon addressing cross-cutting needs for DOE-NE irradiation testing by providing higher fidelity, real-time data, with increased accuracy and resolution from smaller, compact sensors that are less intrusive. ${ }^{13}$ The NEET ASI has established the Ultrasonics Transducer Irradiation and Signal Processing Enhancements project because it will enable in-core use of ultrasound-based sensors that are uniquely capable of meeting DOE program enhanced instrumentation needs.

To ensure that NEET in-pile instrumentation research is relevant, sensor enhancements must be able to survive the irradiation conditions of interest to DOE-NE programs. It is also important that the enhanced sensors be able to measure irradiation test condition parameters and sample characterization parameters, such as thermal and structural properties, with the desired accuracy and resolution required by these DOE-NE programs. Information obtained from the various DOE-NE programs that is being used to guide NEET ultrasonic sensor investigations, is reported below. More detailed information is available in the FY-2012 status report. ${ }^{15}$

A key objective of several DOE-NE programs is to understand the performance of candidate fuels and materials during irradiation. Hence, NEET research must produce sensors able to withstand the operating conditions of interest to these DOE-NE programs. It is also important that the enhanced sensors be able to measure test parameters with the desired accuracy and resolution required by these DOE-NE programs and that the sensors be compact to minimize their impact on irradiation test data. Recognizing that DOE-NE program needs change, the NEET program holds annual reviews to ensure that projects continue to meet DOE-NE program needs. Specific details related to current requirements for thermal, fast, and temperature sensors requested by DOE-NE programs for fuels and material irradiations are summarized in this section. 


\subsubsection{Fuel}

In-situ instrumentation is desired to provide real-time data on fuel performance phenomena. Without wireless transmission capabilities, drop-in or static capsule experiments only allow data to be obtained at the endpoint of an experiment. Although material property measurements may be made on samples at the end of the test, such measurements are subject to error because of handling and because measurements are not made under prototypic pressures, fluxes, and/or temperatures. Sensors included in such tests can only provide insights about the integral neutron fluence or peak temperatures. In-situ instrumentation in irradiation tests can provide data showing the evolution of particular phenomena over time.

Clearly, real-time data obtained during an irradiation are advantageous. However, it is important to understand what additional sensors are needed to obtain data with the required accuracy and resolution. As part of this NEET effort, appropriate documents were reviewed ${ }^{2,5,6,7,8,16}$ and cognizant technical experts were contacted $^{3,12,13,14,17}$ to gain insights related to the temperature, flux levels, and fluences proposed for fuel irradiation tests. Results from this review are summarized in Table 1-1.

Table 1-1. Summary of desired parameters for detection during fuel irradiation tests. ${ }^{\mathrm{a}}$

\begin{tabular}{|c|c|c|c|}
\hline \multirow{2}{*}{ Parameter } & \multirow{2}{*}{ Representative Peak Value } & \multicolumn{2}{|r|}{ Desired } \\
\hline & & Accuracy & Spatial Resolution \\
\hline \multirow[t]{4}{*}{ fuel temperature } & Ceramic LWR - $1400^{\circ} \mathrm{C}$ & \multirow[t]{4}{*}{$2 \%$} & \multirow{4}{*}{$\begin{array}{l}1-2 \mathrm{~cm} \text { (axially); } \\
0.5 \mathrm{~cm} \text { (radially) }\end{array}$} \\
\hline & Ceramic SFR- $2600^{\circ} \mathrm{C}$ & & \\
\hline & Metallic SFR $-1100^{\circ} \mathrm{C}$ & & \\
\hline & TRISO HTGR $-1250^{\circ} \mathrm{C}$ & & \\
\hline \multirow[t]{4}{*}{ cladding temperature } & Ceramic LWR $-<400{ }^{\circ} \mathrm{C}$ & \multirow[t]{3}{*}{$2 \%$} & \multirow[t]{3}{*}{$1-2 \mathrm{~cm}$ (axially) } \\
\hline & Ceramic SFR - $650^{\circ} \mathrm{C}$ & & \\
\hline & Metallic SFR - $650^{\circ} \mathrm{C}$ & & \\
\hline & TRISO GCFR & NA & NA \\
\hline \multirow[t]{4}{*}{ pressure in fuel rod plenum } & Ceramic LWR - $5.5 \mathrm{MPa}$ & \multirow[t]{4}{*}{$5 \%$} & \multirow[t]{4}{*}{$\mathrm{NA}^{\mathrm{b}}$} \\
\hline & Ceramic SFR-8.6 MPa & & \\
\hline & Metallic SFR - 8.6 MPa & & \\
\hline & HTGR-NA & & \\
\hline $\begin{array}{l}\text { LWR, SFR, and HTGR fission gas } \\
\text { release (amount and composition) }\end{array}$ & $0-100 \%$ of inventory & $10 \%$ & NA \\
\hline \multirow{3}{*}{$\begin{array}{l}\text { LWR and SFR fuel and cladding } \\
\text { dimensions (includes fuel / cladding } \\
\text { gap size); HTGR- NA }\end{array}$} & Initial Length, $1 \mathrm{~cm}$ & $1 \%$ & NA \\
\hline & Outer diameter/Strain, $0.5 \mathrm{~cm} / 5-10 \%$ & $0.1 \%$ & NA \\
\hline & Fuel-Cladding Gap (0-0.1 mm) & $0.1 \%$ & NA \\
\hline \multirow{3}{*}{$\begin{array}{l}\text { LWR, SFR, and HTGR fuel } \\
\text { morphology/microstructure/ } \\
\text { cracking/ constituent redistribution }\end{array}$} & Grain size, $10 \mu \mathrm{m}$ & $5 \%$ & $1-10 \mu \mathrm{m}$ \\
\hline & Swelling/Porosity, 5-20\% & $2 \%$ & \\
\hline & Crack formation and growth & $2 \%$ & $10-100 \mu \mathrm{m}$ \\
\hline \multirow[t]{2}{*}{ fuel thermal properties } & $\begin{array}{c}\text { Thermal conductivity } \\
\text { Ceramic: }<8 \mathrm{~W} / \mathrm{mK} \text {; Metallic: }<50 \mathrm{~W} / \mathrm{mK} \text {; } \\
\text { TRISO pebble/compact: } 4-12 \mathrm{~W} / \mathrm{mK}\end{array}$ & $4 \%$ & $<1 \mathrm{~cm}$ (radially) \\
\hline & $\begin{array}{l}\text { Density (inferred from changes in length, diameter, } \\
\text { porosity, etc.) } \\
\text { Ceramic: }<11 \mathrm{~g} / \mathrm{cm}^{3} ; \text { Metallic: }<50 \mathrm{~g} / \mathrm{cm}^{3} \\
\text { TRISO pebble } / \mathrm{compact}^{2} 2.25 \mathrm{~g} / \mathrm{cm}^{3 \mathrm{c}}\end{array}$ & $2 \%$ & NA \\
\hline \multirow{2}{*}{$\begin{array}{l}\text { real-time thermal and fast neutron } \\
\text { flux for estimating fluence and fuel } \\
\text { burnup for fuel irradiations }\end{array}$} & Thermal neutron flux $-\sim 1-5 \times 10^{14} \mathrm{n} / \mathrm{cm}^{2}-\mathrm{s}$ & $1-10 \%$ & $5 \mathrm{~cm}$ (axially) \\
\hline & Fast neutron flux $(\mathrm{E}>1 \mathrm{MeV})-\sim 1-5 \times 10^{14} \mathrm{n} / \mathrm{cm}^{2}-\mathrm{s}$ & $15 \%$ & $5 \mathrm{~cm}$ (axially) \\
\hline
\end{tabular}

a. Representative peak values, accuracy, and resolution are based on engineering judgement by cognizant program experts.

b. NA-Not Applicable.

c. Value dependent upon particle packing fraction and matrix. 


\subsubsection{Materials}

As noted within Ref. 5, there are many different types of materials within a Light Water Reactor (LWR); over 25 different metal alloys can be found within the primary and secondary systems, not to mention the concrete containment vessel, instrumentation and control, and other support facilities. Over the forty-year lifetime of a LWR, internal structural components may expect to see up $\sim 10^{22} \mathrm{n} / \mathrm{cm}^{2}$ in a Boiling Water Reactor (BWR) and $\sim 10^{23} \mathrm{n} / \mathrm{cm}^{2}$ in a Pressurized Water Reactor (PWR) (E > 1 MeV), corresponding to $\sim 7$ dpa and $70 \mathrm{dpa}$, respectively. The neutron irradiation field can produce large property and dimensional changes in materials. Such changes occur primarily via five radiation damage processes: radiation-induced hardening and embrittlement, phase instabilities from radiation-induced or -enhanced segregation and precipitation, irradiation creep due to unbalanced absorption of interstitials versus vacancies at dislocations, volumetric swelling from cavity formation, and high temperature helium embrittlement due to formation of helium-filled cavities on grain boundaries. Extending the service life of a reactor will increase neutron fluence and susceptibility to radiation damage (although new damage mechanisms are possible). Likewise, when one considers the additional conditions proposed within DOE-NE programs for NGNP and SFR operation, material performance becomes more complex.

As part of this NEET effort, appropriate documents were reviewed $4,5,7,8,9,18$ through 21 and cognizant technical experts ${ }^{3,14,17}$ were contacted to gain insights related to the temperature, flux levels, and fluences proposed for irradiation tests to evaluate new high temperature alloys, candidate structural materials, and graphites.Currently, most materials irradiations are relying on Post Irradiation Examination (PIE) to characterize material properties after an irradiation is completed. However, enhanced in-pile instrumentation offers the potential for increased accuracy higher fidelity data since measurements are obtained at the conditions of interest. Currently-requested accuracies and resolutions for these materials are listed in Table 1-2. 
Table 1-2. Summary of desired parameters for detection during materials irradiation tests. ${ }^{\text {a,b }}$

\begin{tabular}{|c|c|c|c|}
\hline \multirow[b]{2}{*}{ Parameter } & \multirow[b]{2}{*}{ Representative Peak Values } & \multicolumn{2}{|c|}{ Desired } \\
\hline & & Accuracy & $\begin{array}{c}\text { Spatial } \\
\text { Resolution }\end{array}$ \\
\hline \multirow[t]{4}{*}{ Material temperature distribution } & LWRS Fuel Cladding- $>1200^{\circ} \mathrm{C}$ & \multirow[t]{3}{*}{$2 \%$} & \multirow{3}{*}{$\begin{array}{l}1-2 \mathrm{~cm} \text { (axially); } \\
0.5 \mathrm{~cm} \text { (radially) }\end{array}$} \\
\hline & LWRS Vessel and Internal Materials- $500^{\circ} \mathrm{C}$ & & \\
\hline & HTGR and LWRS high temperature alloys- $950^{\circ} \mathrm{C}$ & & \\
\hline & HTGR Graphite - 600 to $1200{ }^{\circ} \mathrm{C}$ & $\begin{array}{l} \pm 50^{\circ} \mathrm{C} \text { (axially) } \\
\pm 40^{\circ} \mathrm{C} \text { (radially) }\end{array}$ & NA \\
\hline \multirow[t]{2}{*}{$\begin{array}{l}\text { Material dimensional changes due to } \\
\text { swelling }\end{array}$} & $\begin{array}{l}\text { Initial Specimen Length, } \\
\text { HTGR Graphite - } 2.54 \mathrm{~cm}\end{array}$ & $1 \%$ & NA \\
\hline & $\begin{array}{c}\text { Outer diameter/Strain, } \\
\text { LWR vessel and internal materials }-0.5 \mathrm{~cm} / 5-10 \%\end{array}$ & $0.1 \%$ & NA \\
\hline \multirow{3}{*}{$\begin{array}{l}\text { Material morphology/ } \\
\text { microstructure/cracking/ constituent } \\
\text { redistribution }\end{array}$} & $\begin{array}{c}\text { Grain size, } \\
\text { LWR vessel and internal materials }>10 \mu \mathrm{m}\end{array}$ & $5 \%$ & $1-10 \mu \mathrm{m}$ \\
\hline & $\begin{array}{c}\text { Swelling/Porosity, } \\
\text { LWR vessel and internal materials } 5-20 \%\end{array}$ & $2 \%$ & $10-100 \mu \mathrm{m}$ \\
\hline & $\begin{array}{c}\text { Crack formation and growth } \\
\text { LWR vessel and internal materials }>10 \mu \mathrm{m}\end{array}$ & $2 \%$ & $10-100 \mu \mathrm{m}$ \\
\hline \multirow[t]{4}{*}{ Material thermal properties } & $\begin{array}{c}\text { Thermal conductivity } \\
\text { HTGR Graphite }<80 \mathrm{~W} / \mathrm{m}-\mathrm{K}\end{array}$ & $4 \%$ & $<1 \mathrm{~cm}$ (radially) \\
\hline & $\begin{array}{c}\text { Thermal conductivity } \\
\text { LWR vessel and internal materials } \sim 50 \mathrm{~W} / \mathrm{m}-\mathrm{K}\end{array}$ & $5-20 \%$ & $<1 \mathrm{~cm}$ \\
\hline & $\begin{array}{c}\text { Thermal coefficient of expansion; } \\
\text { HTGR Graphite - 5\% }\end{array}$ & $2 \%$ & $\mathrm{NA}^{\mathrm{c}}$ \\
\hline & $\begin{array}{c}\text { Density (estimated from changes in length, diameter, } \\
\text { porosity, etc.) } \\
\text { HTGR Graphite }-0.5 \%\end{array}$ & $0.2 \%$ & NA \\
\hline \multirow[t]{5}{*}{$\begin{array}{c}\text { Material mechanical/electrical } \\
\text { properties }\end{array}$} & $\begin{array}{c}\text { Irradiation creep } \\
\text { HTGR Graphite - 3-4\% }\end{array}$ & NA & NA \\
\hline & $\begin{array}{c}\text { Young's modulus } \\
\text { HTGR Graphite - 3-4\% }\end{array}$ & NA & NA \\
\hline & $\begin{array}{c}\text { Electrical resistivity } \\
\text { HTGR Graphite - 3-4\% }\end{array}$ & NA & NA \\
\hline & $\begin{array}{c}\text { Poisson's ratio } \\
\text { HTGR Graphite - 3-4\% }\end{array}$ & NA & NA \\
\hline & $\begin{array}{c}\text { Fracture toughness, shear strength } \\
\text { HTGR Graphite - 3-4\% }\end{array}$ & NA & NA \\
\hline \multirow{2}{*}{$\begin{array}{l}\text { Material irradiation neutron flux for } \\
\text { estimating fluence }\end{array}$} & Thermal neutron flux - $\sim 1-5 \times 10^{14} \mathrm{n} / \mathrm{cm}^{2}-\mathrm{s}$ & $1-10 \%$ & $5 \mathrm{~cm}$ (axially) \\
\hline & Fast neutron flux $(\mathrm{E}>1 \mathrm{MeV})-\sim 1-5 \times 10^{14} \mathrm{n} / \mathrm{cm}^{2}-\mathrm{s}$ & $15 \%$ & $5 \mathrm{~cm}$ (axially) \\
\hline
\end{tabular}

a. Representative peak values, accuracy, and resolution are based on engineering judgement and are preliminary.

b. Only LWRS and NGNP irradiation information available for a limited number of parameters at this time.

c. NA-Not Available.

\subsubsection{NEET Project Objectives}

The objective for Task 1 of this project is to evaluate the performance of ultrasonic transducer materials in high flux/high temperature irradiation environments. This project leverages results from an ATR NSUF-funded PSU-led MITR irradiation and supports an irradiation evaluation of the most promising candidate piezoelectric and magnetostrictive transducer materials. Building upon recent results from ultrasonic sensor investigations, an in-depth review of prior piezoelectric and magnetostrictive transducer irradiations was used to develop a list of candidate materials for irradiation evaluation. In addition, a design 
for an instrumented-lead irradiation test capsule and a test plan for evaluating ultrasonic transducer materials were developed. As noted previously, to maximize the benefit of this irradiation test, cognizant technical experts associated with various DOE-NE programs, such as ARC, LWRS, SMRs, FCRD, NGNP and ATR NSUF efforts, were contacted. In addition, recent results from piezoelectric irradiation studies in foreign research reactors were considered. This test will be an instrumented lead test, such that real time signals are received from the transducers. Such a test will enable an accurate measure of the performance and possible degradation of candidate transducer materials under irradiation. This test will also provide fundamental data on piezoelectric and magnetostrictive material performance in irradiation environments, which can be directly compared. Prior tests either tested too few samples, or samples that were too dissimilar, for such a comparison. This additional information may enable further application of ultrasonic technologies in the future.

The objective for Task 2 is to enhance signal processing methods used to support various types of ultrasonic sensors. Ultrasonic instrumentation is a well-developed technology widely used in nuclear and non-nuclear applications; however, several improvements are required for successful implementation in irradiation tests. The harsh testing conditions that ultrasonic sensors must survive are likely to reduce signal to noise ratios, complicating identification of signal features. Therefore, a primary goal of Task 2 work will be the development of methods to improve signal to noise ratio. Ultrasonic sensors utilize several different signal characteristics (i.e. delay time, resonant frequency, attenuation, acoustic impedance, etc.) for monitoring the many parameters previously identified. Enhanced methods of processing these signal characteristics, specific for in-pile ultrasonic applications, are being developed in Task 2 that are capable of acquiring and processing signals specific to parameters of interest to DOE-NE programs.

\subsection{Report Content and Organization}

The objective of this report is to document FY-2013 progress in the Ultrasonic Transducer Irradiation and Signal Processing Enhancements project. Section 2 summarizes the status of efforts to support the PSU-led ultrasonic transducer material irradiation test, including a description of the irradiation test conditions, a discussion of the materials to be included in the test, and a description of the proposed test capsule. Section 3 lists requirements for enhanced signal processing capabilities needed for future development of in-pile ultrasound based sensor systems. Section 4 summarizes key accomplishments for this project and outlines tasks required to complete this effort, and Section 5 lists references cited in this document.

Additional information on the motivation for this work, as well as preliminary designs of the test capsule and transducers, is available in the FY-2012 status report. ${ }^{15}$ This report also includes descriptions of representative irradiation reactors in which new sensor technologies may be deployed, and descriptions of representative fuel and materials and irradiation test conditions that are of interest to DOE-NE programs. The FY-2012 status report also provides additional details about the physical parameters that must be detected during irradiation tests with desired accuracies. 
NEET In-Pile Ultrasonic Sensor Enablement-FY 2013 Status Report

September 2013 


\section{TASK 1: ULTRASONIC TRANSDUCER IRRADIATION TEST}

There is a need to improve the ability to characterize and track the evolution of nuclear fuel degradation during irradiation. To address this, new irradiations are conducted in higher flux MTRs that can accelerate irradiation effects observed in commercial power plants. Ultrasonic measurements have a long and successful history of use for out-of-core materials characterization applications, including detection and characterization of degradation and damage. ${ }^{22}$ PIEs have successfully shown that fuel microstructural parameters, such as porosity and grain size, can be correlated to ultrasonic velocity. ${ }^{23}$ According to Villard, ${ }^{24}$ frequency requirements for such measurements are restricted to greater than $10 \mathrm{MHz}$. However, lower frequencies can be used for some applications, such as ultrasonic thermometry, where frequency requirements may be $100-150 \mathrm{kHz}$ or lower. ${ }^{25}$

The development of ultrasonic tools to perform a variety of in-pile measurements requires a fundamental understanding of the behavior of ultrasonic transducer materials in high-radiation environments. While a number of irradiation studies of ultrasonic transducers have been described in the literature, a one-to-one comparison of these studies is difficult, as the materials and irradiation test conditions often differ. In addition, the tests to date are generally at lower flux/fluences than what might be seen in US MTRs. ${ }^{15}$ As a result, a series of experiments to baseline the performance of ultrasonic transducer materials (in terms of change in sensitivity as a function of temperature and irradiation) are necessary to support the irradiation test.

Task 1 of this project leverages ATR-NSUF funded efforts to develop a test capsule design and define irradiation conditions for evaluating most promising candidate piezoelectric and magnetostrictive transducer materials and designs. From the onset of this effort, an instrumented lead test was proposed, such that real time signals are received from the transducers being tested. Collecting real time signals will enable an accurate measure of the performance and possible degradation of candidate transducer and sensor materials under irradiation. In addition, laboratory testing will be completed to verify that transducer materials will survive anticipated thermal conditions.

Results of this irradiation test will enable development of ultrasonic sensors for in-pile measurements, including fuel and material morphology changes, fission gas composition and pressure measurements, fuel and material geometry changes, and temperature. Results from these tests will provide a method for selecting optimum ultrasonic transducer materials for different in-pile measurements and guide the development of signal processing tools to enhance the measurement to demonstrate the intended in-pile measurements.

A PSU proposal for an ultrasonic transducer irradiation was selected by the ATR NSUF for irradiation in the MITR. This section documents the progress and status of this effort. First, the design of the test capsule and changes that have been made to the capsule design, and the reasons for them are described. Next, the current transducer designs are discussed. Results of out of pile tests performed to date are also described. Additional details of FY-2012 work were documented in the FY-2012 status report. ${ }^{15}$ A flowchart describing the responsibilities of each collaborating organization and the scheduling for completing the activities associated with Task 1 is shown in Figure 2-1. 


\section{Component Selection}

Design and Fabrication

INL

Design and fabrication of

magnetostrictive transducers

\section{PSU}

Design and fabrication of

Piezoelectric transducers
PSU

Cable evaluation

and selection

PNNL $\cdot$ ANL

Connector evaluation and selection

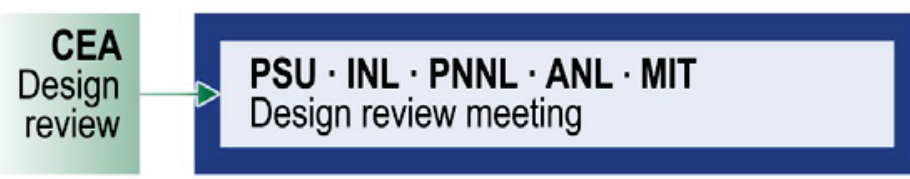

\section{Equipment Transfer}

INL $\cdot$ PSU

Transducers to

MIT for irradiation

Transducers to PSU

for out-of-pile testing
Ultrasonic testing equipment to MIT for irradiation
Ultrasonic testing equipment to PSU for out-of-pile testing

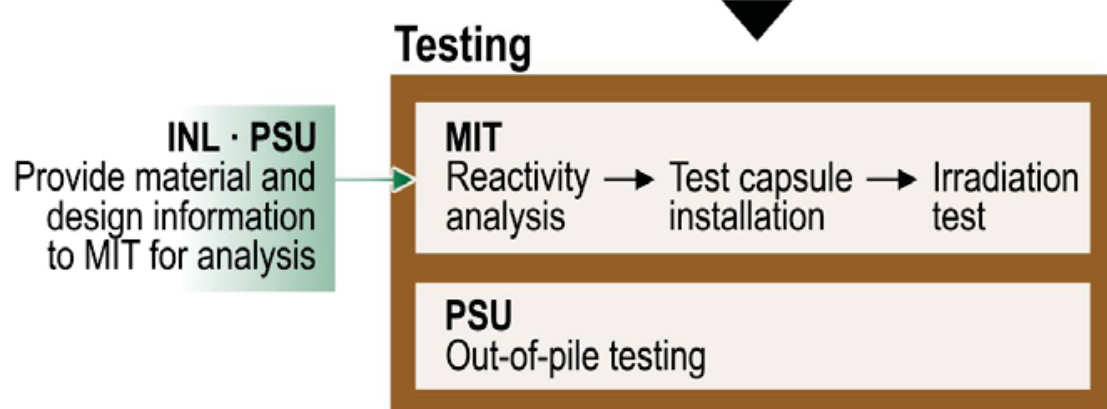

\section{Analysis}

PSU

Data collection $\rightarrow$

and analysis

INL $\cdot$ PNNL $\cdot$ ANL
Data analysis
validation

MIT

Post irradiation examination

\section{Reporting}

$\mathrm{NL} \cdot \mathrm{PNNL} \cdot \mathrm{ANL}$

Report input

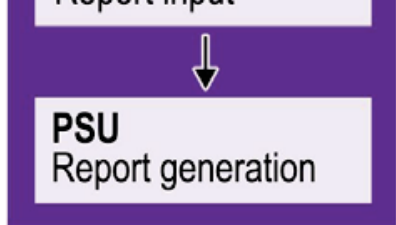

Key: FY 2012 (completed)

FY 2013 (completed)

FY 2013 (in progress)

FY 2014

Figure 2-1. Task 1 schedule flow chart. 


\subsection{Test Capsule Design}

\subsubsection{MITR Design}

As noted above, the ultrasonics transducer irradiation will be performed in the MITR. Relevant MITR design information is summarized here to provide perspective about the design of the ultrasonics transducer capsule and test conditions developed by this project.

The MITR is a tank-type research reactor. ${ }^{26}$ It is currently licensed for $6 \mathrm{MW}$ operation. The identified irradiation position and flux condition at the MITR are summarized in Table 2-1.

Table 2-1. Representative dimensions and flux levels in MITR.

\begin{tabular}{|c|}
\hline MITR In-Core Experimental Facility \\
\hline $\begin{array}{c}\text { Irradiation tube for sample capsule irradiation or isotope production } \\
\text { (instrumented or unistrumented.) }\end{array}$ \\
\hline Coolant loops that replicate conditions in both pressurized and boiling reactors. \\
\hline Facilities for testing mechanical properties of samples in a light water reactor environment. \\
\hline High temperature irradiation facility for materials irradiations in inert gas (He/Ne mix) at \\
temperatures up to $1400^{\circ} \mathrm{C}$. \\
\hline Size: \\
Space for 3 capsules \\
Max in-core volume $\sim 46$ mm ID x $610 \mathrm{~mm}$ long \\
Neutron Flux $\left(\mathrm{n} / \mathrm{cm}^{2}-\mathrm{s}\right):$ \\
Thermal: $\sim 3.6 \times 10^{13}$ \\
Fast: up to $4 \times 10^{13}(\mathrm{E}>1 \mathrm{MeV})$ \\
\hline
\end{tabular}

The ATR-NSUF/PSU test capsule will have a $46 \mathrm{~mm}$ diameter and $610 \mathrm{~mm}$ length. Temperature control will be afforded by a helium/neon gas gap with adjustable gas composition. The anticipated test temperature will be approximately $450{ }^{\circ} \mathrm{C}$. It is proposed that the test exceed fast neutron fluences of prior piezoelectric transducer irradiations (e.g., $>1 \times 10^{21} \mathrm{n} / \mathrm{cm}^{2}$ at $\mathrm{E}>1.0 \mathrm{MeV}$ ). In order to observe rapid changes at relatively low fluences, it is planned to start the test with the reactor coming to power slowly. The anticipated steady state fast flux $(>1 \mathrm{MeV})$ in the test location will be $3.2 \times 10^{13} \mathrm{n} / \mathrm{cm}^{2}$-s with the reactor running at $5.8 \mathrm{MW}$ power. This level of fast flux will require approximately 362 full power days, or 23 calender months, to reach the desired fluence level.

Figure 2-2 shows the position of the test capsule within the MITR core. Based on thermal analysis performed at MIT, the expected operating temperature for the test at steady state will be between 350 and $450{ }^{\circ} \mathrm{C}$. After startup, the target temperature will be controlled by variation of the composition of a gas gap between the test capsule and the in-pile experiment tube. The gas will be a mixture of helium and neon. It is planned that the reactor will perform a slow startup ramp. This will enable data collection at low fluence levels, where early failures were observed in prior piezoelectric transducer irradiations. Once the reactor reaches a power level sufficient to maintain the target temperature, the experiment will be placed on automatic temperature control (helium/neon mix) for the remainder of reactor startup. 


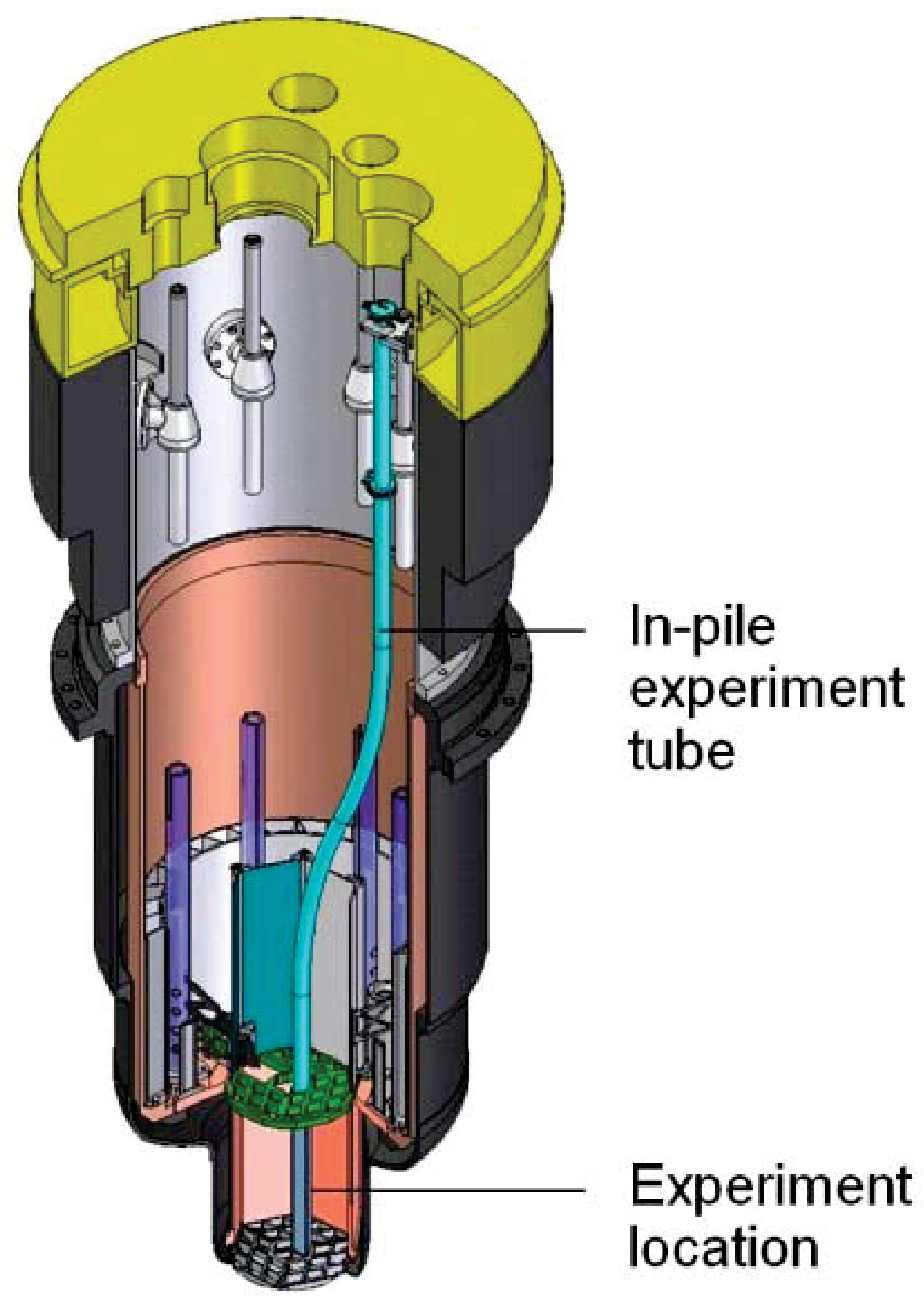

Figure 2-2. Position of irradiation capsule within MITR core.

\subsubsection{Capsule Design}

A preliminary test capsule design is shown in Figure 2-3. The design incorporated room for six piezoelectric and three magnetostrictive sample capsules as well as instrumentation for monitoring temperature, thermal flux, and gamma heating. 


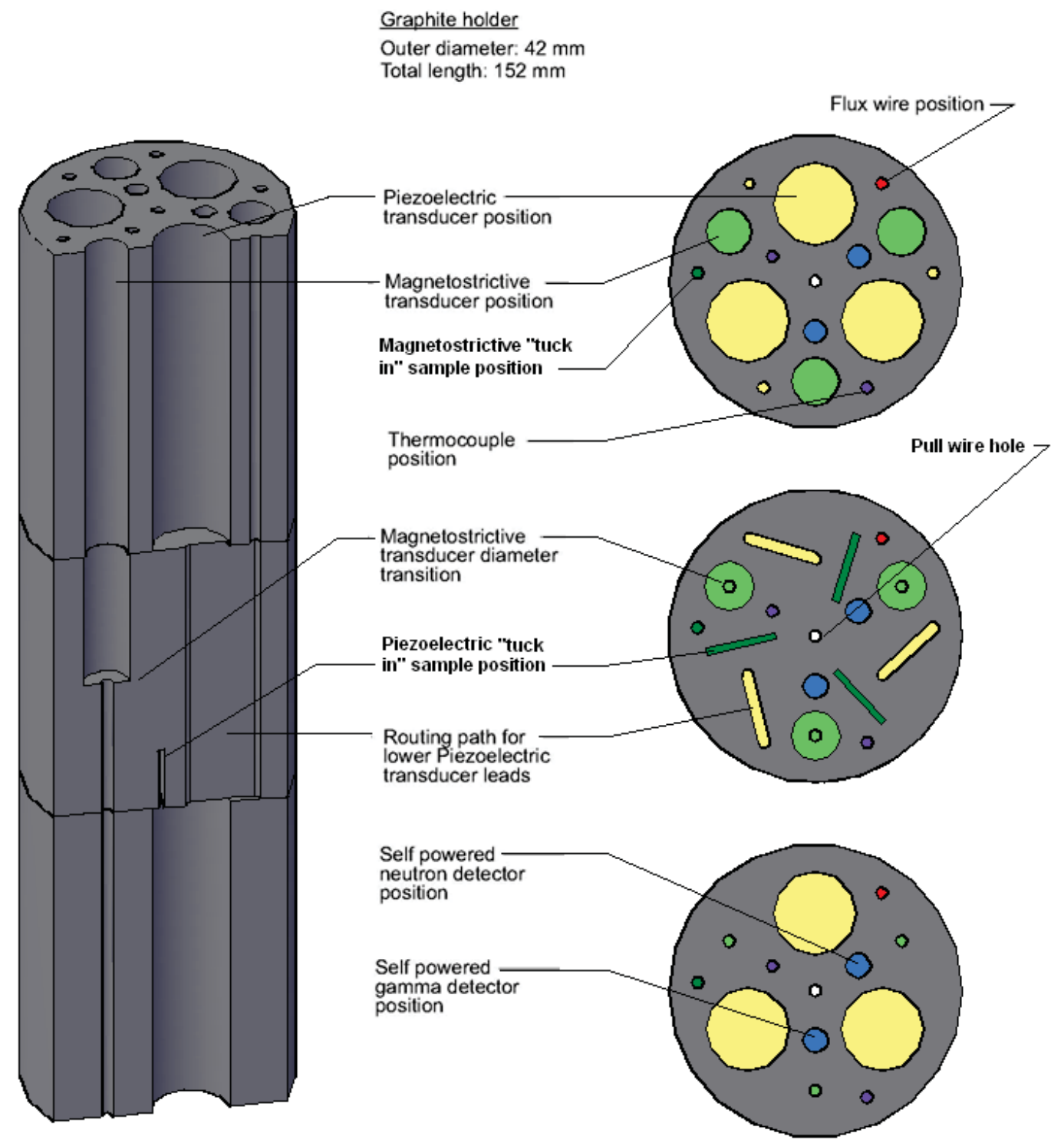

Figure 2-3. Initial test capsule graphite sample holder design with sample and instrumentation positions detailed.

During FY-2013, gamma heating evaluations were completed indicating that the FY-2012 capsule design would lead to transducer materials being exposed to temperatures that could cause thermal degradation.As a result, the planned location of the test capsule within the MITR core was changed to a lower flux region, and the test capsule design was modified to reduce temperatures. The refinement was necessary as thermal analyses performed by MIT indicated that temperatures could reach over $540^{\circ} \mathrm{C}$ with the preliminary design. Figures 2-4 and 2-5 show calculated temperatures for the initial design of the graphite sample holder, and the transducer outer surfaces. 


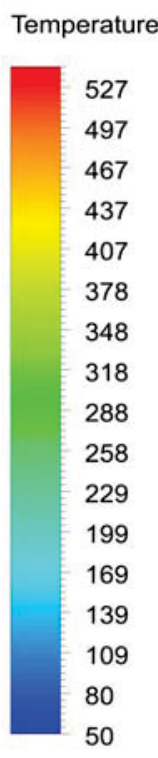

[C]

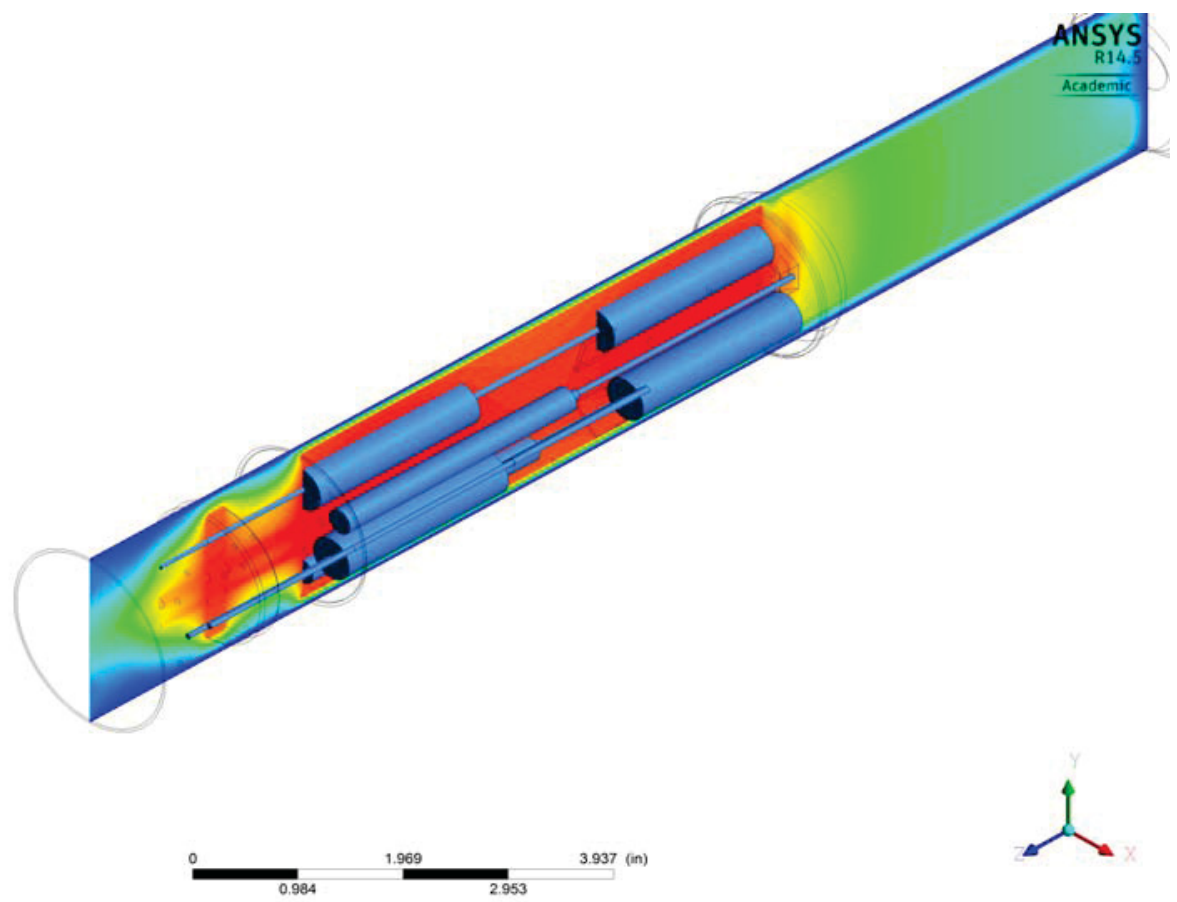

Figure 2-4. Calculated temperature distribution within graphite sample holder. Temperatures are in degrees Celsius.

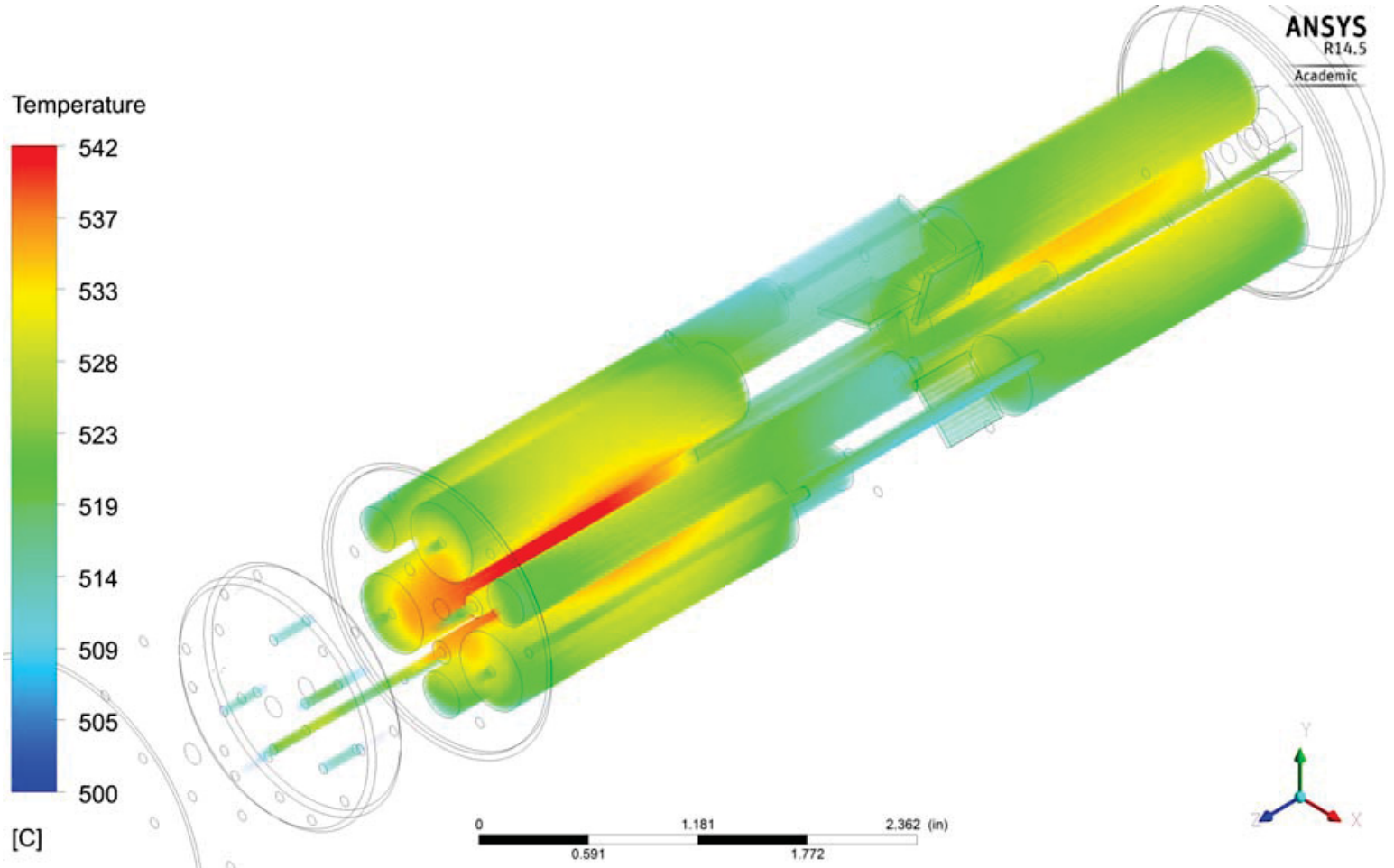

Figure 2-5. Calculated surface temperature distribution for test transducers. Temperatures are in degrees Celsius. 
To reduce temperatures, it was necessary to reduce the included mass of the capsule. Furthermore, the number of transducers were reduced (eliminating materials that laboratory evaluations deemed less promising and unnecessary redundancies) and the graphite holder was redesigned. The final design accommodates four piezoelectric transducers and two magnetostrictive transducers. All of the originally selected transducer materials will still be included, but only the $\mathrm{ZnO}$ transducer will have a redundant transducer. A key feature of the redesigned capsule is the staggering of the vertical position of each piezoelectric transducer. This feature spreads the mass of the transducers across a greater volume, and reduces the concentrated gamma heating. All of the originally proposed instrumentation will also be included, as will loose samples of each candidate transducer material. The final design is shown in Figure 2-6. Temperatures for the redesigned capsule are predicted to reach a maximum of approximately $430{ }^{\circ} \mathrm{C}$, as shown in Figure $2-7$ (thermal analysis of the redesigned capsule).
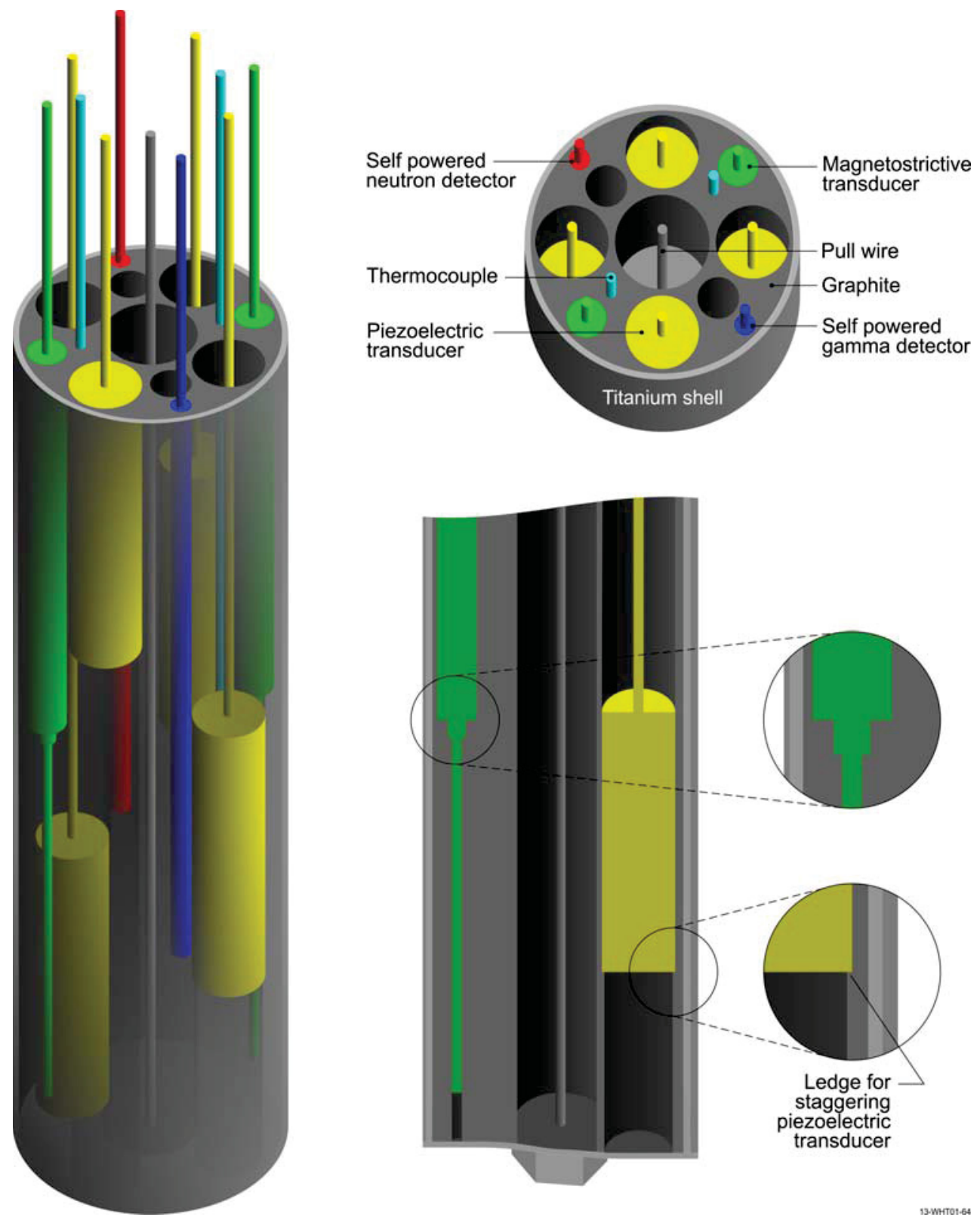

Figure 2-6. Final test capsule graphite sample holder design with sample and instrumentation positions detailed. 

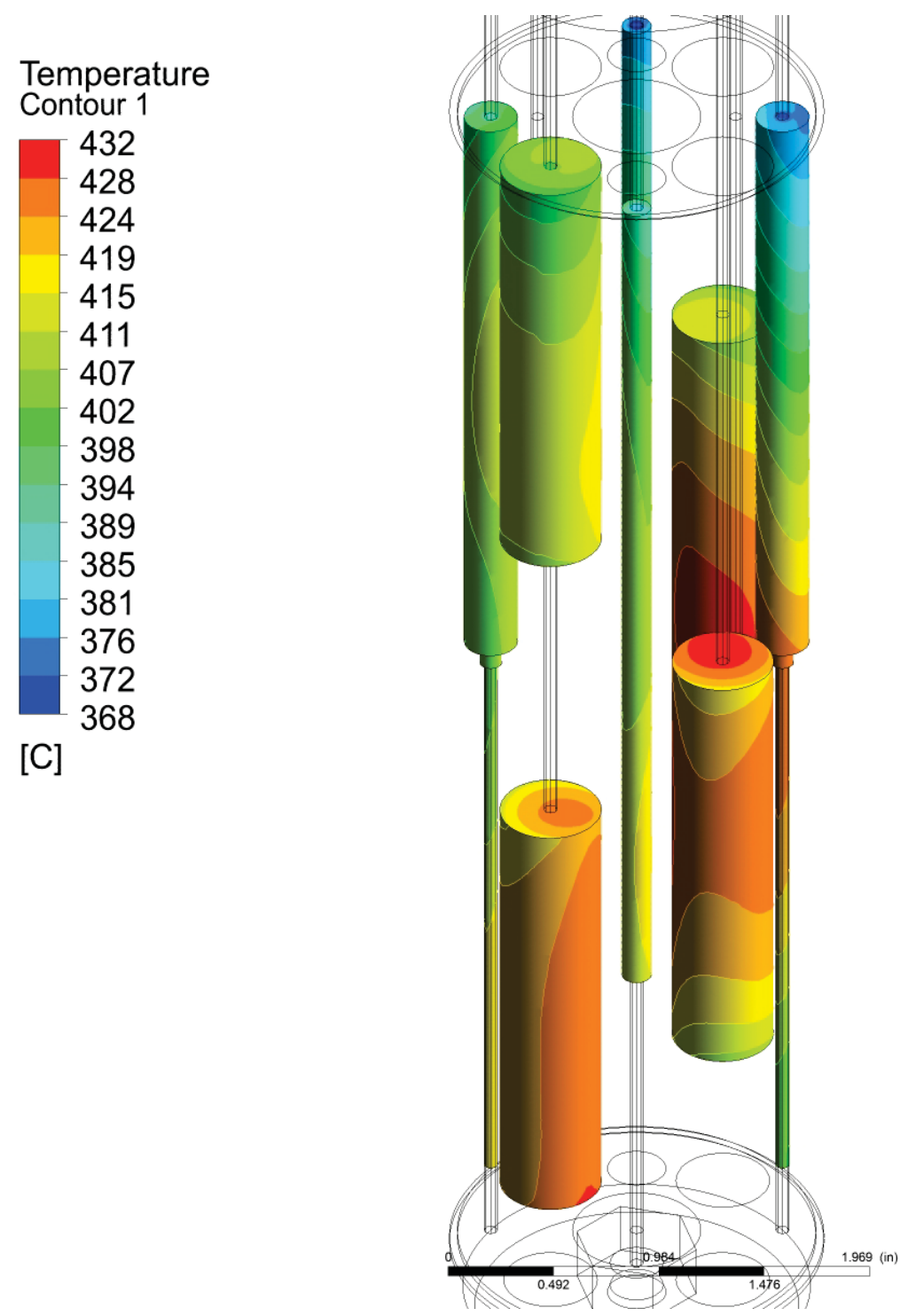

\section{ANSYS \\ $\frac{\text { R14.5 }}{\text { Academic }}$}

432

428

424

419

415

411

407

402

398

394

389

385

381

376

372

[C]

Figure 2-7. Results of thermal analysis of redesigned test capsule predicting lower transducer surface temperatures. Temperatures are in degrees Celsius.

\subsubsection{Sensors}

Clearly, in order to characterize ultrasonic transducer degradation during irradiation, real-time data are needed to characterize the irradiation test conditions. As discussed within this section, efforts have been made to include diverse and redundant instrumentation.

Irradiation test temperatures will be monitored online by two Type-K thermocouples. Thermal neutron flux will be monitored online by a vanadium emitter Self Powered Neutron Detector (SPND). Gamma flux will be monitored online by a platinum emitter Self Powered Gamma Detector (SPGD). A schematic diagram of the SPND and SPGD is shown in Figure 2-8 (Sensors have identical configuration and dimensions, selected sheath materials (Inconel 600), and insulation material $\left(\mathrm{Al}_{2} \mathrm{O}_{3}\right)$. Differences are limited to the selected emitter (e.g., vanadium for the SPND and platinum for the SPGD). 


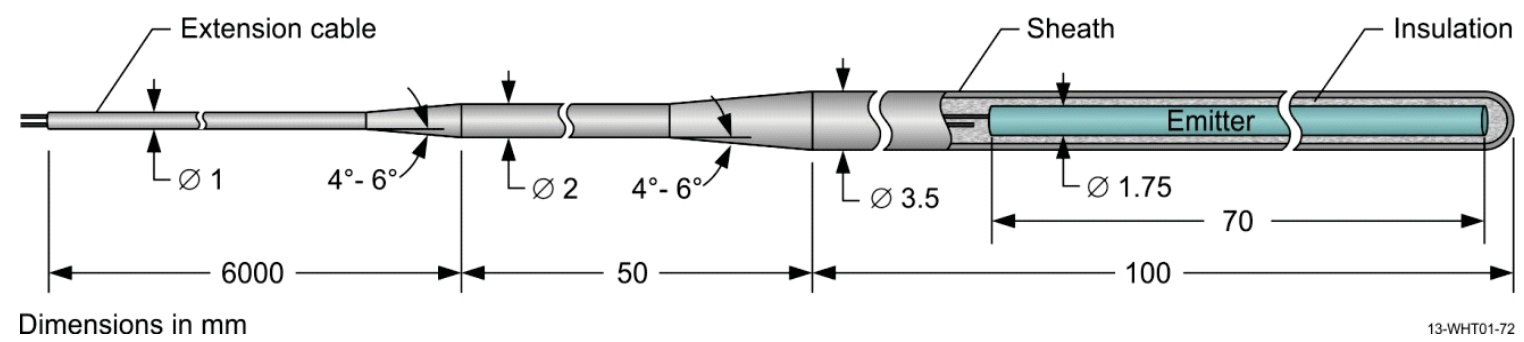

Figure 2-8. Schematic diagram of SPND and SPGD (dimensions are the same for each).

In addition to the thermocouples, the maximum temperature reached at selected locations during the irradiation will be verified using melt wires encapsulated in a quartz tube. Five wire compositions will be included, with melting temperature ranging between approximately 327 and $514{ }^{\circ} \mathrm{C}$. Melting temperatures of the wires have been verified using a Differential Scanning Calorimeter (DSC). Melt wire compositions and melting temperatures are listed in Table 2-2, and a photo of a quartz-encapsulated melt wire capsule is shown in Figure 2-9. Integrated thermal and fast neutron fluences at selected locations will be evaluated through post irradiation analysis of Fe-Ni-Cr flux wires.

Table 2-2. Compositions and melting temperatures of melt wires.

\begin{tabular}{|c|c|}
\hline Material Composition, $\%$ & Melting Temperature, ${ }^{\circ} \mathbf{C}$ \\
\hline $100 \mathrm{~Pb}$ & 327.5 \\
\hline $94 \mathrm{Zn}-6 \mathrm{Al}$ & 381.0 \\
\hline $85 \mathrm{Te}-15 \mathrm{Sn}$ & 401.0 \\
\hline $100 \mathrm{Zn}$ & 419.6 \\
\hline $80 \mathrm{Sb}-20 \mathrm{Zn}$ & $507.8-514.3$ \\
\hline
\end{tabular}

\section{netiont - vas}
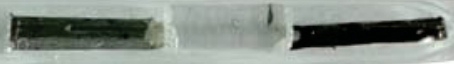

Figure 2-9. Example melt wire capsule with five wire types.

\subsection{Candidate Transducers}

To generate and receive ultrasonic pulses and signals, the two most commonly used methods rely on piezoelectric or magnetostrictive materials. Ultrasonic measurements using piezoelectric transducers have been demonstrated over a wide frequency range from $\mathrm{kHz}$ and up to $\mathrm{GHz}$; however, most non-destructive examination (NDE), materials characterization, and process monitoring are performed in the range from 1-20 $\mathrm{MHz}$, making piezoelectric transduction ideal. The current capabilities of magnetostrictive transducers are typically limited to operation at frequencies up to the order of $100 \mathrm{kHz}$, though recent research suggests that higher frequencies may be possible for small transducers. However, mechanical coupling as well as enhanced guided wave mode generation makes magnetostrictive transduction ideal for low frequency measurements, such as ultrasonic thermometry. ${ }^{27}$ Therefore, radiation tolerant sensors which utilize piezoelectric or magnetostrictive materials are being considered as candidates for instrumentation and US MTR testing. 
Prior studies have shown that typical piezoelectric and magnetostrictive materials used in transducers degrade when subjected to high temperature and radiation. ${ }^{28-33}$ Candidate magnetostrictive and piezoelectric materials must, therefore, be carefully selected; and transducer assemblies must be carefully designed. As discussed below, only limited radiation effects data are available to guide this process.

Additional studies and tests are needed to select the optimum transducer materials for various in-pile ultrasonic sensors. The MITR irradiation test and associated laboratory supported by this project will provide important information for selecting appropriate transducers for ultrasonic sensors.

FY-2013 efforts focused on developing and fabricating transducer designs developed and fabricated for the MITR irradiation. As reported in this subsection, both piezoelectric and magnetostrictive transducer designs were developed, successfully fabricated, and shipped to MIT.

\subsubsection{Piezoelectric Materials}

A literature review was completed at the beginning of this effort to identify candidate piezoelectric transducer materials. This section highlights characteristics of the piezoelectric transducer materials that were ultimately selected for inclusion in this irradiation. The piezoelectric materials selected for inclusion in the irradiation test are summarized in Table 2-3. Additional details related to candidate piezoelectric transducer materials may be found in Reference ${ }^{15}$.

Table 2-3. Candidate piezoelectric materials.

\begin{tabular}{|c|c|c|c|c|}
\hline Material & Composition & $\begin{array}{c}\text { Transition } \\
\text { Temperature, }\end{array}{ }^{\circ} \mathbf{C}$ & Transition Type & Comments \\
\hline Bismuth Titanate & $\mathrm{Bi}_{4} \mathrm{Ti}_{3} \mathrm{O}_{12}$ & 909 & Curie Temperature & $\begin{array}{c}\text { Thought to be radiation tolerant. Most } \\
\text { promising previously tested candidate. } \\
\text { Good baseline comparator. }\end{array}$ \\
\hline Aluminum Nitride & $\mathrm{AlN}$ & 2200 & Melt & $\begin{array}{c}\text { Thought to be highly radiation tolerant. } \\
\text { Very high temperature capability. }\end{array}$ \\
\hline Zinc Oxide & $\mathrm{ZnO}$ & $>1500$ & Melt & $\begin{array}{c}\text { Thought to be highly radiation tolerant. } \\
\text { High temperature capability. }\end{array}$ \\
\hline
\end{tabular}

\section{Aluminum Nitride (AlN)}

Aluminum nitride is a relatively new material, as far as bulk single crystals are concerned. In fact, the work of Parks \& Tittmann ${ }^{34}$ with this material is the first of its sort. In the past, thin film AlN has been shown to be unaffected by gamma irradiation up to $18.7 \mathrm{MGy}^{35}$ and temperatures of $1000{ }^{\circ} \mathrm{C} .{ }^{36,37}$ Moreover, this material has been explicitly cited in numerous independent studies as a highly radiation tolerant ceramic. ${ }^{38}$

Further, tests of bulk single crystal AlN in a TRIGA nuclear reactor core showed this material to be completely unaffected by a fast and thermal neutron fluence of $1.85 \times 10^{18} \mathrm{n} / \mathrm{cm}^{2}$ and $5.8 \times 10^{18} \mathrm{n} / \mathrm{cm}^{2}$ respectively and a gamma dose of $26.8 \mathrm{MGy} .{ }^{34}$ This work along with that of $\mathrm{Yano}^{39}$ and Ito $^{40}$ have indicated that the ${ }^{14} \mathrm{~N}(\mathrm{n}, \mathrm{p}){ }^{14} \mathrm{C}$ is not of much concern.

\section{Bismuth Titanate $\left(\mathrm{Bi}_{4} \mathrm{Ti}_{3} \mathrm{O}_{12}\right)$}

The literature review has revealed bismuth titanate to be the most promising material tested to date. ${ }^{41}$ However, this material lost roughly $60 \%$ of its one way piezoelectric response at a fast neutron fluence of $10^{20} \mathrm{n} / \mathrm{cm}^{2}$, which may preclude it from being used for longer duration in-pile irradiations. The decrease in the signal response is in agreement with the statements made by Trachenko, ${ }^{38}$ namely that disordered Ti-O-Ti bridges of highly covalent character form in titanates when subjected to ballistic radiation effects. Regardless, given that this material has shown the greatest promise to date of previously tested materials, $\mathrm{Bi}_{4} \mathrm{Ti}_{3} \mathrm{O}_{12}$ has been selected as a baseline in the proposed research. 


\section{Zinc Oxide (ZnO)}

Zinc oxide is found in the Wurzite structure, as is AlN, and has been cited as a highly radiation tolerant material. ${ }^{38}$ The evaluated nuclear data files (ENDF) do not show any detrimental nuclear cross sections, and this material possesses a high transition temperature and moderate piezoelectric coupling.

\subsubsection{Piezoelectric Transducers}

The design of the piezoelectric transducers developed for this irradiation is based on the design used in a prior Training, Research, Isotopes, General Atomics (TRIGA) test of AlN. ${ }^{34}$ The piezoelectric transducers use pressure for coupling the piezoelectric element to the stainless steel waveguide. Electrical contact with the piezoelectric element is also achieved through application of pressure. A backing layer behind the piezoelectric sensor provides damping (preventing excessive "ringing" of the transducer) and acts as an electrode. The electrical connection from the lead-in cable to the graphite backing is made through a stainless steel plunger, which is isolated from the housing by alumina insulation. The connection to ground is made through the housing, with the waveguide acting as the second electrode. During the irradiation, transducer performance will be measured using pulse/echo measurements through the stainless steel waveguide. A schematic of the design is shown in Figure 2-10.

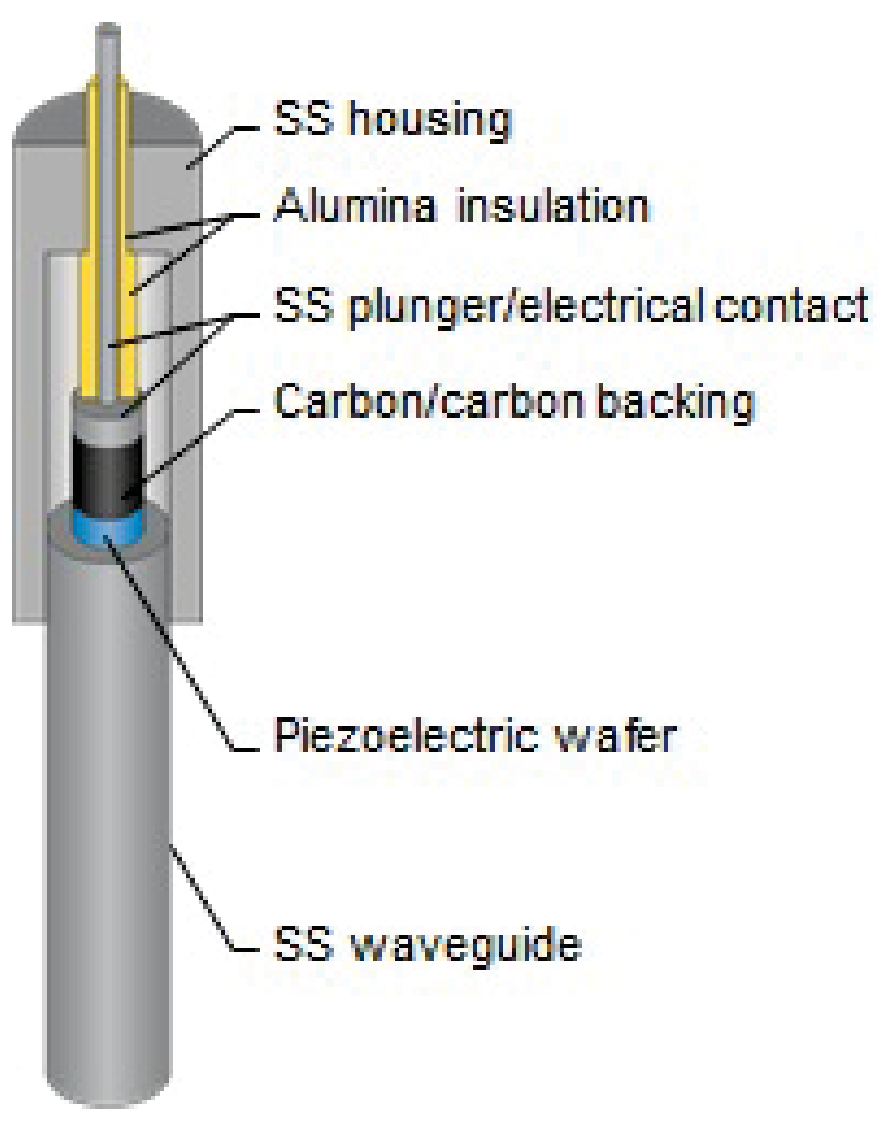

Figure 2-10. Piezoelectric transducer design. 
Figure 2-11 shows a piezoelectric transducer prior to assembly. Figure 2-12 shows a close up view of a $\mathrm{ZnO}$ piece in the as-received state.

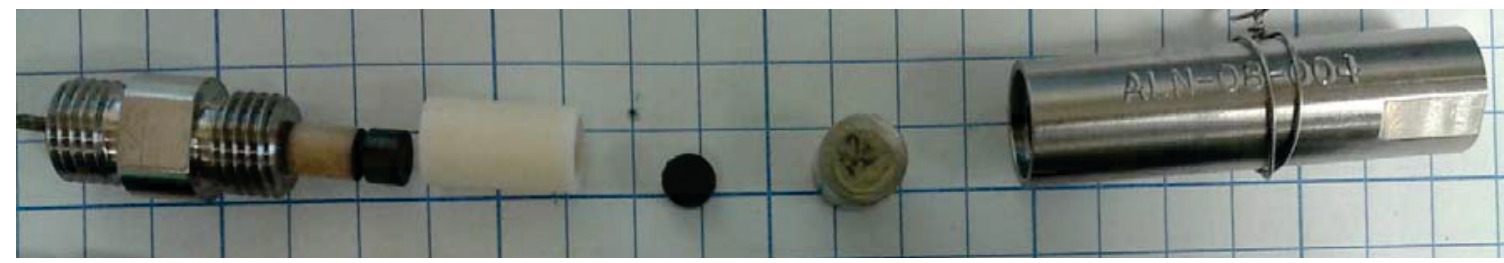

Figure 2-11. Two piezoelectric transducers laid out prior to assembly.

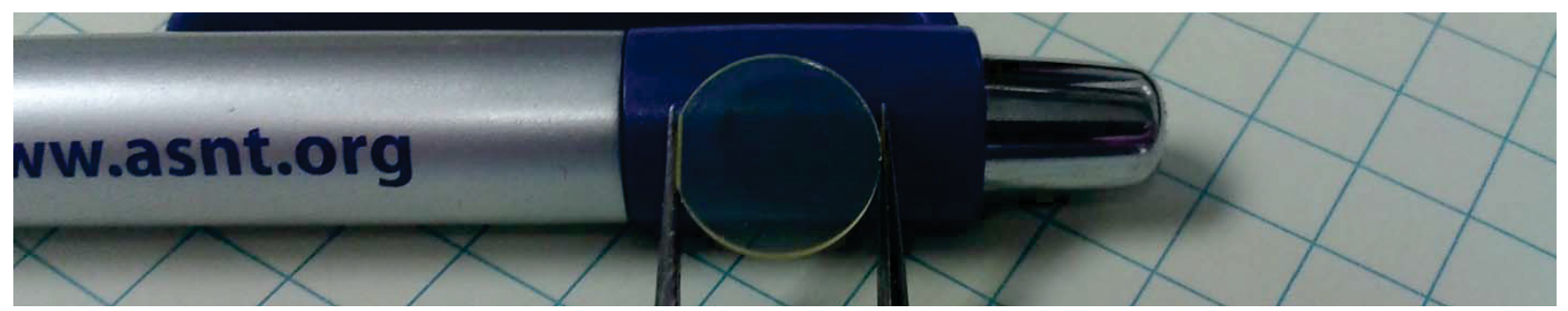

Figure 2-12. $\mathrm{ZnO}$ piezoelectric chip prior to incorporation into transducer.

Originally a slip joint was made from an alumina insulation bead to mechanically hold the lead cable to the plunger. However, upon delivery of the samples to MIT, it was discovered that this method did not provide enough support. A picture of the original alumina sleeve design is shown in Figure 2-13(a). The sleeve is bonded to the wire sheath using a castable mineral cement while the lead wire is left exposed in center of the sleeve. The plunger is fit into the sleeve making mechanical contact with the lead wire. To compensate for this, a strain relief fixture was designed to stabilize the connection. The transducer with the strain relief sleeve installed is show in Figure 2-13(b).

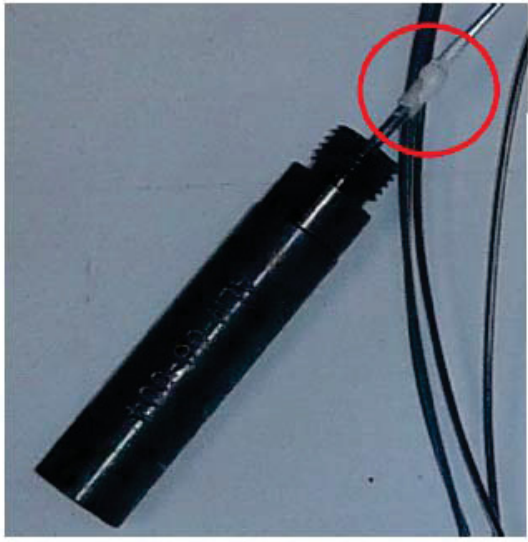

(a)

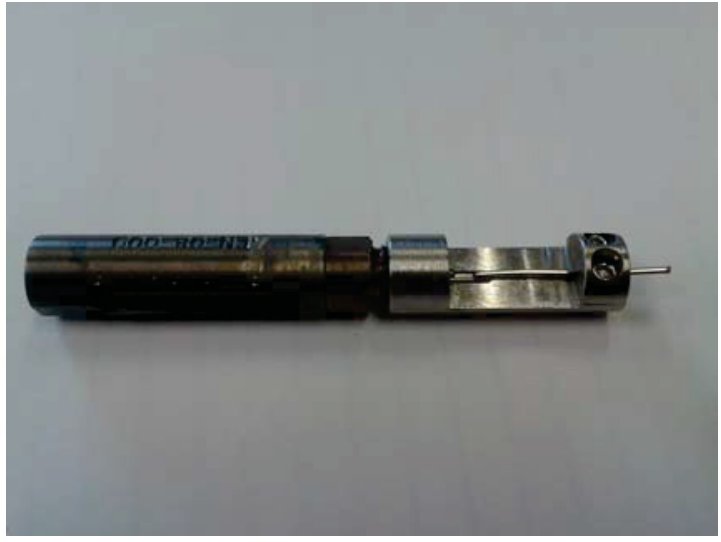

(b)

Figure 2-13. Piezoelectric transducer (a) Original transducer with alumina bead connection to extension cable. (b) Enhanced transducer with strain relief sleeve designed to support connection to cable.

\subsubsection{Magnetostrictive Materials}

A literature review was also completed at the beginning of this effort to identify candidate magnetostrictive transducer materials. This section highlights characteristics of the magnetostrictive materials that were ultimately selected for inclusion in this irradiation. Additional details related to candidate magnetostrictive 
transducer materials may be found in Reference ${ }^{15}$. These loose samples will be evaluated during post irradiation examination. The magnetostrictive materials selected for inclusion in the irradiation test are summarized in Table 2-4.

Table 2-4. Candidate magnetostrictive materials.

\begin{tabular}{|c|c|c|c|}
\hline Material & Composition & Key Properties & Comments \\
\hline Remendur & $49 \mathrm{Fe}-49 \mathrm{Co}-2 \mathrm{~V}$ & $\begin{array}{c}70-100 \mu \text {-strain max. magnetostriction, } \\
\text { curie temperature } 950{ }^{\circ} \mathrm{C}\end{array}$ & $\begin{array}{c}\text { No longer manufactured, identical/similar } \\
\text { alloys available, possible activation of cobalt }\end{array}$ \\
\hline Galfenol & Fe-14Ga-NbC & $\begin{array}{c}100-400 \mu \text {-strain max. magnetostriction, } \\
\text { curie temperature } 700{ }^{\circ} \mathrm{C}\end{array}$ & $\begin{array}{c}\text { Relatively new, small amounts of data, } \\
\text { difficult to acquire }\end{array}$ \\
\hline Arnakrome 4 & $95 \mathrm{Fe}-5 \mathrm{Cr}$ & $\begin{array}{c}10-40 \mu \text {-strain max. magnetostriction, } \\
\text { curie temperature } 770{ }^{\circ} \mathrm{C}\end{array}$ & Low magnetostriction \\
\hline Arnakrome 5 & $92 \mathrm{Fe}-8 \mathrm{Mn}$ & $\begin{array}{c}10-40 \mu \text {-strain max. magnetostriction, } \\
\text { curie temperature } 770{ }^{\circ} \mathrm{C}\end{array}$ & Low magnetostriction \\
\hline
\end{tabular}

\section{Remendur}

Remendur has the most history of use in nuclear applications of all the magnetostrictive alloys, having been used previously for short duration thermometry applications. ${ }^{42-45}$ Remendur has relatively high Curie temperature and magnetostriction. Although Remendur is no longer commercially available, several identical alloys are available under different names. INL also has a supply of Remendur which is being used for this test.

\section{Galfenol $^{46}$}

Galfenol is a relatively new alloy of iron and gallium. Galfenol is a member of the "giant" magnetostrictive alloys and has a very large saturation magnetostriction. It also has an appropriately high Curie temperature. Neither constituent element reacts strongly with neutron radiation.

\section{Arnokrome $^{T M}$ (Arnold Magnetics ${ }^{47-49}$ )}

Arnold Magnetics produces several magnetostrictive alloys, Arnokrome 3, Arnokrome 4, and Arnokrome 5. Arnokrome 3 contains cobalt and has much lower magnetostriction than Remendur, and is therefore not of interest in the current study. Arnokrome 4 and 5 have similar magnetostriction to Arnokrome 3, but without the presence of cobalt. The Arnokrome alloys appear less promising than the other selected materials and due to the reduced number of available positions will not be included in the irradiation as a transducer material. However, samples of Arnokrome 4 and 5, along with all the other magnetostrictive and piezoelectric materials, will be included in the irradiation test as loose 'tuck-in' samples.

\subsubsection{Magnetostrictive Transducers}

The magnetostrictive design developed for this effort was influenced by prior research to develop an appropriate transducer for use in ultrasonic thermometry applications. ${ }^{42-45}$ It should also be acknowledged that magnetostrictive transducer fabrication efforts were leveraged from FCRD-funded efforts to develop an ultrasonic thermometer. A schematic of the magnetostrictive transducer design is shown in Figure 2-14. Dimensions of the transducer housing pieces are shown in Figure 2-15. 


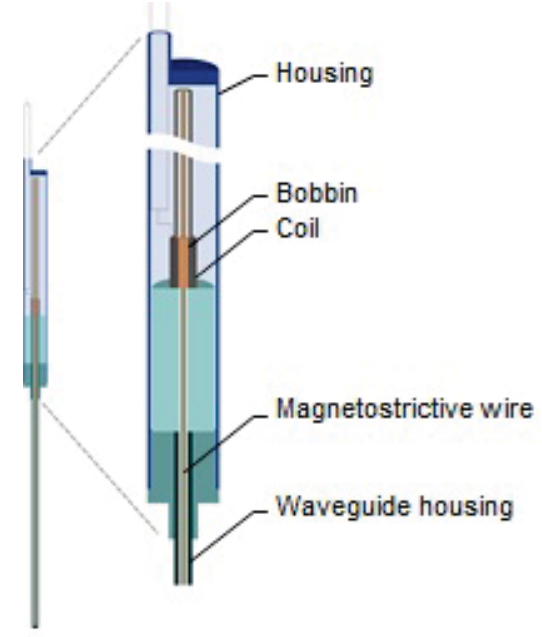

Figure 2-14. Magnetostrictive transducer design.
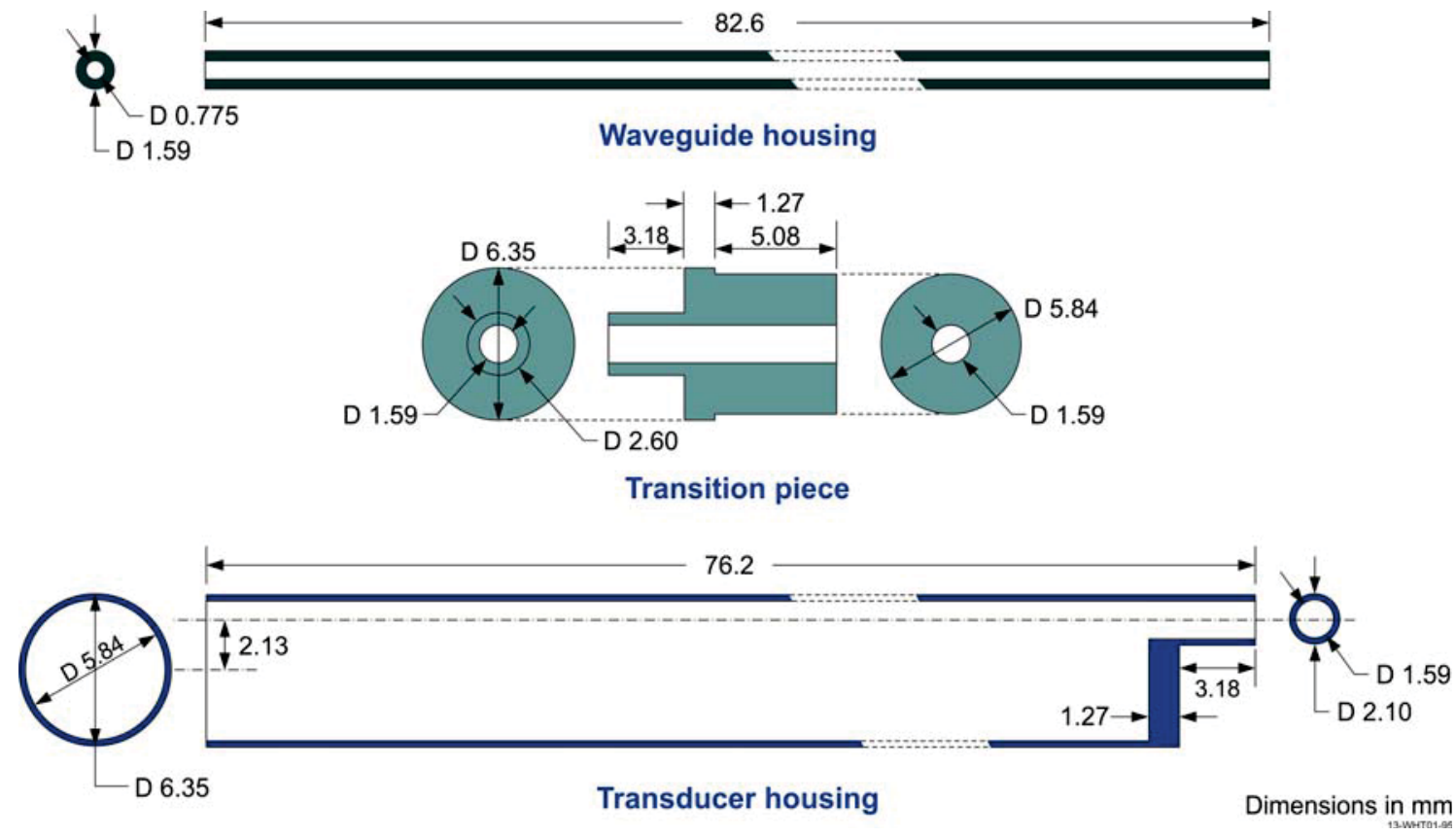

Figure 2-15. Transducer housing dimensions.

The original design planned for inclusion in this irradiation included a biasing magnet, a spring, and a damper. The biasing magnets were eliminated based on results from laboratory evaluations. It was determined that the spring (used to tension the waveguide and reduce contact with the housing) and the damper (used to eliminate reverberations) were unnecessary and complicated the construction process. Incidental contact between the waveguide and housing can have an effect on the shape of the recorded signal, but the transducer performance will be judged based on changes in the signal over time, so the initial shape is not critical. The damper eliminates multiple pass through signals, which will be used to determine attenuation characteristics of the waveguide material.

Construction of high temperature magnetostrictive transducers is a multi-step process that involves several heat treatment steps. First, the coil is formed by wrapping several layers of silver-palladium wire around an alumina bobbin [see Figure 2-16(a)]. The wire is coated in a standoff insulation (a particulate alumina 
silica mix with a burnable binder). The insulation requires a heat treatment step prior to high temperature use and becomes brittle after heating [see Figure 2-16(b)]. After heat treatment, the coil is coated with alumina cement and heat treated a second time (to cure the cement) [see Figure 2-16(c)]. The coil is then securely placed in a fixture, and the wire leads are laser welded to a high temperature capable coaxial cable (one lead to the center conductor and one to the sheath) [see Figure 2-16(d)]. As the welds are fragile, the end of the cable and the coil are coated in another layer of alumina cement and cured. The magnetostrictive wire (previously welded to the waveguide) is then threaded through the coil. The assembly is then placed into a pre-fabricated transducer housing and seal welded [see Figure 2-16(e)].

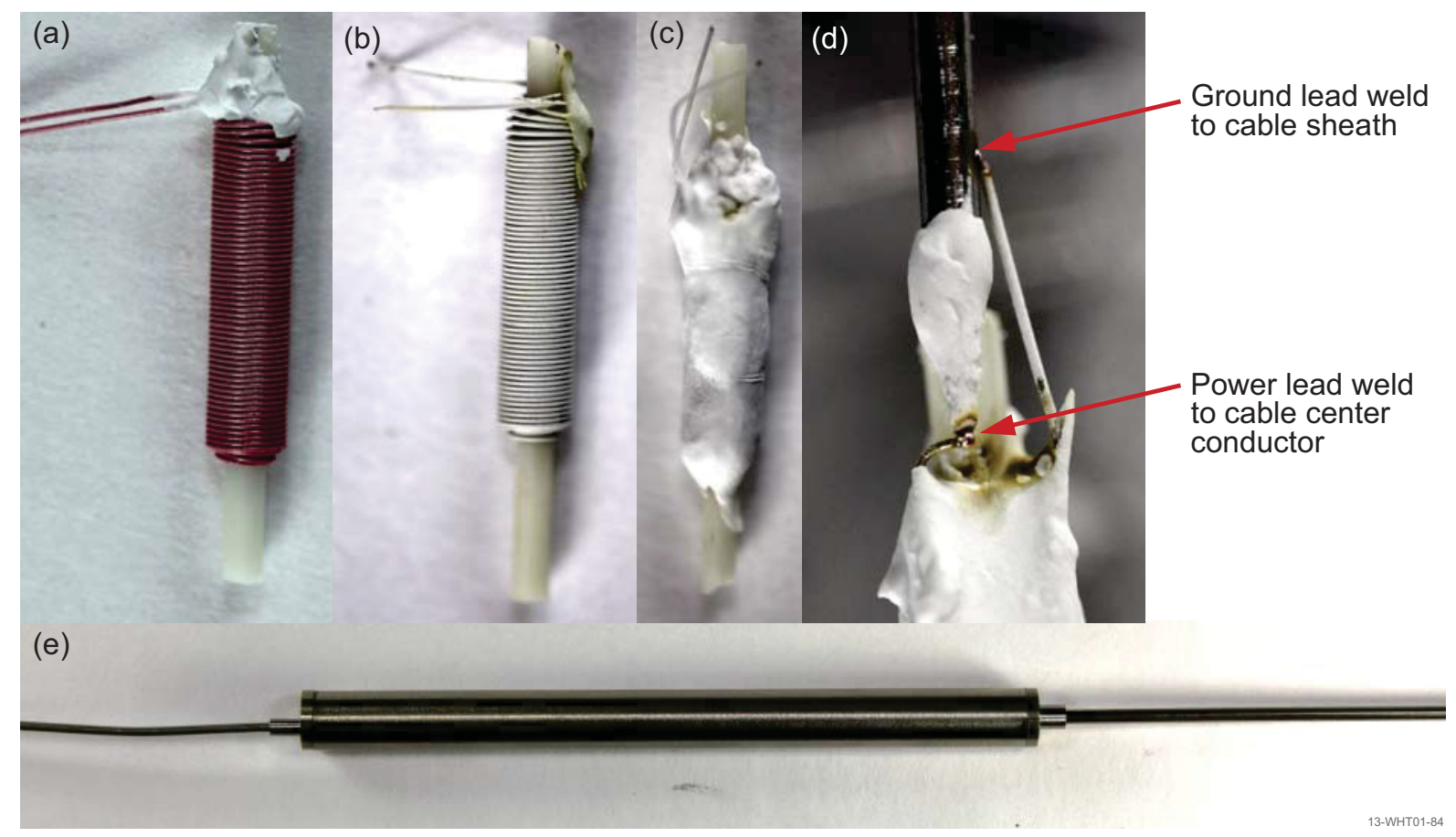

Figure 2-16. Steps involved in making high temperature capable magnetostrictive transducer.

\section{Removal of Biasing Magnets}

Both Alnico and Samarium-Cobalt magnets were considered because they have high Curie temperatures and have been shown to maintain magnetic field strength in irradiation conditions. ${ }^{50,51}$ Neither magnet is considered as an ideal candidate because both contain significant amounts of cobalt and would activate during irradiation. Through initial testing and development of the magnetostrictive transducer design, it was discovered that the magnetostrictive materials will become weakly magnetized when exposed to the driving magnetic pulse at test temperatures. As a result, the magnetostrictive wires become "self-biased" and no longer need a biasing magnet to achieve adequate signal strength. In fact, the presence of a biasing magnet becomes detrimental, as it cancels out the self-biasing effect. A heat treatment of the assembled transducer is required prior to operation of the transducer. The identified heat treatment consists of slowly heating the transducer to $500{ }^{\circ} \mathrm{C}$ and holding temperature for 30 minutes, while pulsing the transducer coil (using the same settings that will be used in the irradiation). This results in a stronger signal than that produced by the biasing magnets. The effect is likely not permanent, but samples have been observed to still be self-biased months after heat treatment. As temperatures in the irradiation and laboratory furnace tests will be in the range of $350-450{ }^{\circ} \mathrm{C}$, the self-biasing effect should continuously renew. 


\subsubsection{Coupling}

The coupling between the sample and the transducer is another important factor that affects ultrasonic energy transmission efficiency, ultrasonic signal quality, transducer design and complexity, and transducer reliability and life. Generally, coupling between a transducer and a sample is a critical design consideration which has a great impact on the performance of a transducer. However, in this irradiation test, the transducer is the sample under consideration. In the case of the piezoelectric transducers, a stainless steel waveguide is used to create a time delay between the generated and received signal. Coupling between the transduction material (the sample being tested) and the waveguide is achieved through mechanical pressure and enhanced by the use of either a silver paste or a thin aluminum foil between the transducer crystal and the waveguide. As the changes that will be studied and used to characterize performance are relative in nature (i.e., reduction in signal strength over time), the importance of the coupling is reduced (assuming it does not change significantly over time). In the case of the magnetostrictive transducers, coupling between the transduction material and a waveguide could be accomplished by welding (as in the preliminary design). However, as the transduction is accomplished by magnetic coupling between a coil and a short section of the magnetostrictive wire, the wire itself may be used as the waveguide; and no mechanical coupling is required.

\subsection{Cables and Connectors}

During FY-2013, efforts were made to finalize the requirements and procure cabling and connectors for this irradiation test. For each transducer or sensor in the MITR irradiation, there are three cables. First, the cable from the transducer to the connection in the MIT Junction Box - this cable is denoted Cable 1. This cable is integral to each transducer, and supplied with the transducer. Second, the cable from the Terminal Box inside the reactor to another box just outside the reactor - this cable is denoted Cable 2 - and a third cable from the junction box outside the reactor to the electronics cabinet. See Figure 2-17 (note that only one of each cable is shown - there will actually be approximately 10 cables: six for the transducers, and four for the sensors).Because there is a fairly large number of cables and because the cables must be flexible enough to be routed through relatively tight and tortuous quarters, the cables must be of small diameter as shown in Figure 2-18 and Table 2-5.

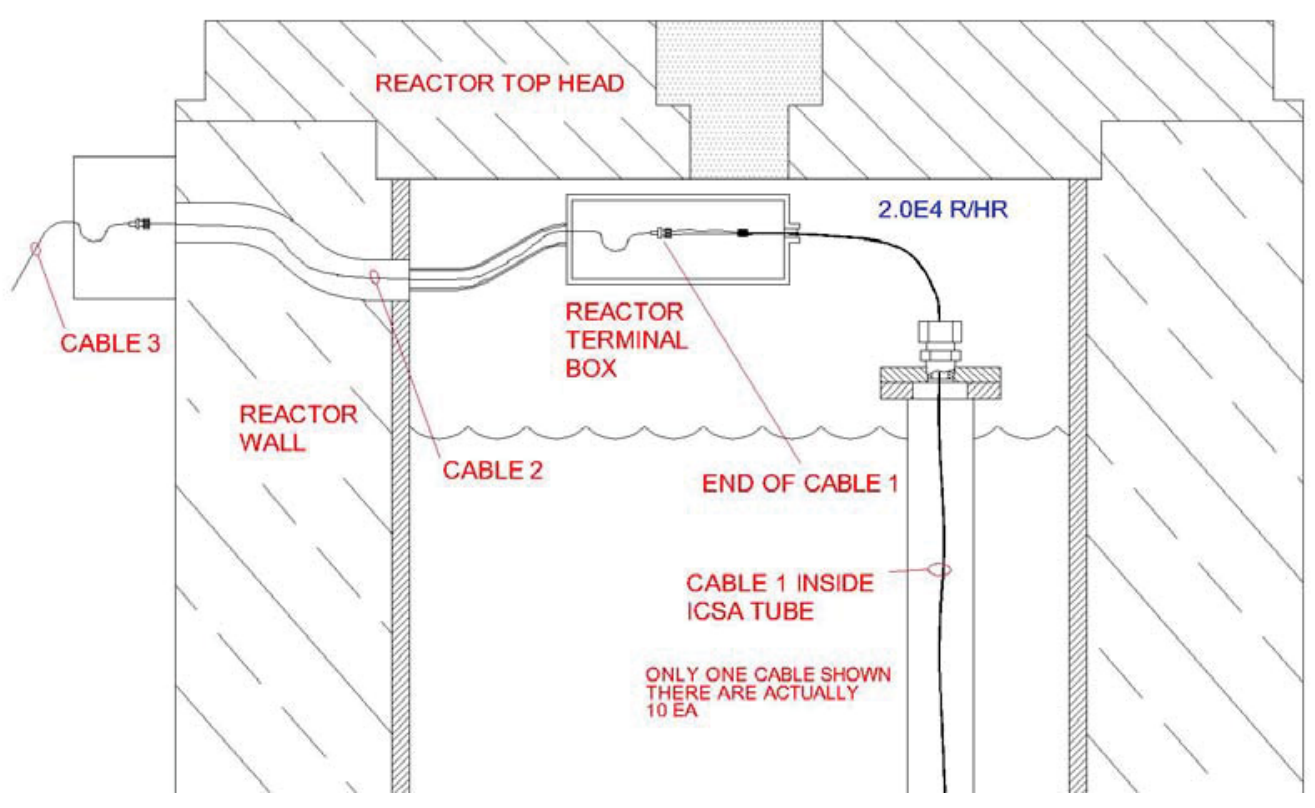

Figure 2-17. Cable details near reactor head. 
Table 2-5. Characteristics of transducer extension cables.

\begin{tabular}{|c|c|c|c|}
\hline & Cable 1 & Cable 2 & Cable 3 \\
\hline Length & $6 \mathrm{~m}$ & $<3 \mathrm{~m}$ & $<16 \mathrm{~m}$ \\
\hline Type & $\begin{array}{l}\text { Co-axial, 50-ohm } \\
\text { impedance, mineral } \\
\text { insulated, metallic } \\
\text { sheath, } 1.0 \mathrm{~mm} \text { OD. }\end{array}$ & $\begin{array}{c}\text { Commercially } \\
\text { available mini co-ax, } \\
50 \text { ohm impedance, } \\
\text { RG-174. }\end{array}$ & $\begin{array}{l}\text { Commercially available } \\
\text { mini co-ax, } 50 \text { ohm } \\
\text { impedance, RG-174. }\end{array}$ \\
\hline Connectors & $\begin{array}{c}\text { Connection to the } \\
\text { transducers will be by } \\
\text { mechanical connections. } \\
\text { Connector at far end is } \\
\text { BNC }\end{array}$ & $\begin{array}{c}\text { Both connectors are } \\
\text { BNC. }\end{array}$ & $\begin{array}{l}\text { Both connectors are } \\
\text { BNC. }\end{array}$ \\
\hline Temperature & $\begin{array}{c}\text { At transducer } \\
\text { connection up to } 450^{\circ} \mathrm{C} \text {, } \\
\text { elsewhere }<70^{\circ} \mathrm{C}\end{array}$ & $\begin{array}{c}<70^{\circ} \mathrm{C} \text { for first few feet } \\
\text { inside reactor, }<40^{\circ} \mathrm{C} \\
\text { outside reactor }\end{array}$ & $<40^{\circ} \mathrm{C}$ \\
\hline Radiation Field & $\begin{array}{c}\mathrm{Up} \text { to } 1 \mathrm{E} 9 \mathrm{R} / \mathrm{hr} \text { at } \\
\text { connection to } \\
\text { transducers diminishing } \\
\text { to } 2 \mathrm{E} 4 \mathrm{R} / \mathrm{hr} \text { at top of } \\
\text { vessel }\end{array}$ & $\begin{array}{l}\text { 2E4 } \mathrm{R} / \mathrm{hr} \text { for first few } \\
\text { feet inside reactor, } \\
\text { negligible outside } \\
\text { reactor wall }\end{array}$ & Negligible \\
\hline
\end{tabular}

CABLE 1 - FROM TRANSDUCER

TO RX JUNCTION BOX

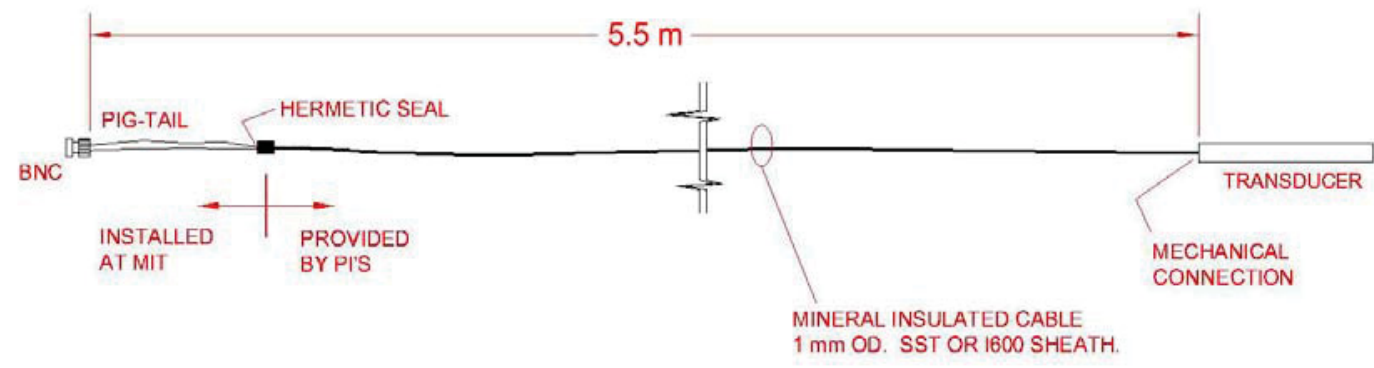

Figure 2-18. Detailed view of transducer cabling. 


\subsubsection{In-Core Cables and Connectors}

To be used in a high-temperature, high-radiation environment, electric cables (previously denoted as "Cable 1" in Figure 2-17 and Table 2-5) and connectors need to be carefully selected to minimize attenuation and to prolong their operational life. Cable and connector sizes also need to be considered due to the number of transducers that will be tested and the constrained feed-through space.

The selected type of excitation/signal cable appears to be adequate for a high-temperature $\left(1000{ }^{\circ} \mathrm{C}\right)$ and high-radiation environment. ${ }^{52}$ This cable uses $\mathrm{SiO}_{2}$ as the annular dielectric and can be obtained with $50 \Omega$ impedance in various diameters. Larger diameters are less flexible, while smaller diameters exhibit higher insertion loss. Once again, this cable must be hermetically sealed to maintain electrical integrity, which requires factory termination. For the purposes of this test, the smallest diameter cable (1 mm OD) appears sufficient.

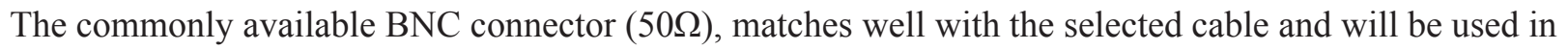
this test. The connector will have to be spliced to the metal sheathed cable after the test capsule has been installed in the reactor.

All of the commercially available BNC connectors contain organic components, such as a Teflon or nylon insulation ring, that will deteriorate, crack or melt when used in high-temperature, high-radiation environment. Therefore, these organic components have to be replaced by ceramic components.

Transducers designed for this test will be contained within sealed housings. Due to the limited space available for the samples, it is preferable to connect the transducer element (electrodes for piezoelectric transducers or signal coil for magnetostrictive transducers) to the signal cable by way of direct welding (i.e. laser welding) or soldering in order to reduce the transducer size.

Thermocoax supplied $\mathrm{SiO}_{2}$ insulated low-capacitance signal transmission cables will be used to transmit and receive from the ultrasonic transducers during the in-pile irradiation testing. The test plan developed for this irradiation specifies a set of mineral insulated (MI) cables that are connected to a junction box just within the top-head of the reactor. Soft cables are used to connect back from the junction box to a second junction box outside the reactor, from where additional cables connect to the instrumentation. This arrangement, while necessary, puts additional burdens on the connectors that are used at each of these junction boxes. Specific requirements that arise from this arrangement are:

- Connectors will need to be attached to the MI cable (to enable connection to the first junction box).

- Connectors used inside the reactor will need to be robust to withstand temperature and humidity environments while maintaining signal integrity.

- The connectors will need to be matched (in impedance) to the cable and the other connector/cable combinations to minimize spurious signals

- The connector-cable junction will need to be well-shielded to minimize interference.

To meet these requirements, several connector types were examined as was the MI cable itself. Attaching a connector directly to the MI cable is a difficult proposition (due to the mechanical rigidity of the cable itself as well its small diameter). The recommended approach is to use a soft cable as a splice, with the connector attached to the soft cable. 
To evaluate the cable splicing procedure, a section of MI cable was acquired and connected to the soft cable using a procedure supplied by ThermoCoax. Laboratory evaluations led to the following observations and recommendations for applying the procedure to the MITR irradiation.

1. Use of non-standard wire strippers damaged the MI outer sheath and caused the insulator and inner conductor to break away.

2. Soft cable prep-work is relatively simple.

3. Due to the relatively small size of the cables (soft cable and MI cable), preparation and assembly with protective gloves in a confined area would be difficult. There is the potential for the splice and/or the connector to be pulled away in the event the connector or cable is used for deploying (or otherwise manipulating) the test capsule.

Recommendation 1 .The success of the procedure depends on the availability of a $1 \mathrm{~mm}$ OD capacity sheath stripper to cut the sheath of the MI cable. Because this is a non-standard dimension (and not readily available on standard wire cutters and wire strippers), a specialized sheath stripper will be supplied to MIT.

Recommendation 2.The preparatory work and splicing of the two cables should be done on a lab-bench prior to deployment of the test capsule.

Recommendation 3.A separate (possibly stainless steel) cable should be incorporated in the capsule for use in hoisting the capsule. This will provide needed strain relief to the coaxial cables used for the ultrasonic tests.

\subsection{Required Out of Pile Tests}

As part of this effort, several laboratory tests will be conducted either prior to or in conjunction with the irradiation test (prior to the test being preferable, as it would allow identification of any systematic problems before the full test is installed in the reactor). These tests are needed to help separate the effects of the neutron radiation from effects of the elevated temperature the test will likely reach while in the reactor. A list of out-of-pile tests is given in Table 2-6.

The primary out-of-pile test will provide insights about the effects of long term (on the same time scale as the irradiation test) operation of prototypic transducers at a temperature closely approximating the expected irradiation temperature $\left(\sim 350-450{ }^{\circ} \mathrm{C}\right)$. This test will provide an understanding of the effects of long term temperature effects on transducer and allow separation of the effects of temperature from the effects caused by the irradiation. The design of test transducers and fixturing (e.g., the graphite holder) should match that used in the MITR irradiation (i.e. same batch of material, same design, similar instrumentation). Longer term tests at room and at higher temperatures will be completed to quantify the performance of the various candidate transducer and coupling materials.

A second out-of-pile test that will be completed is a temperature ramping test in which the transducers are heated over a short time period (on the order of hours) from room temperature to the maximum operating temperature (i.e., Curie temperature). This test will further enable a separation of the temperature effects on the transducers from the irradiation effects, and will be used to identify the maximum operating temperature of each candidate transducer materials. It will also allow a more comprehensive study of the performance of the candidate transducers at temperatures near the estimated irradiation temperature.

Hysteresis measurements may be made simultaneously during the previously-described tests. These measurements will help identify changes in material structure. 
Table 2-6. Planned out-of-pile tests.

\begin{tabular}{|c|c|c|}
\hline Test & Materials & Description \\
\hline $\begin{array}{l}\text { Endurance test } \\
\qquad(\mathrm{ET})\end{array}$ & All candidate materials & $\begin{array}{l}\text { The ET includes operation of candidate transducers at } 300{ }^{\circ} \mathrm{C} \text {. } \\
\text { This test is to be used as a reference for the data collected during } \\
\text { the irradiation test. Two types of endurance tests will be } \\
\text { performed, one at an elevated temperature relative to the nuclear } \\
\text { reactor environmental conditions to accelerate the degradation } \\
\text { process. The other is at the anticipated peak irradiation } \\
\text { temperature of } 450^{\circ} \mathrm{C} \text {. The time necessary for each of these tests } \\
\text { is estimated to range from two weeks to several months. The } \\
\text { samples are to be inserted in the reactor for over a year, so a } \\
\text { several months long test is planned. } \\
\text { This test will allow separation of temperature induced changes } \\
\text { from radiation induced changes, as well as identification of } \\
\text { design flaws. }\end{array}$ \\
\hline $\begin{array}{l}\text { Maximum } \\
\text { operating } \\
\text { temperature } \\
\text { (MOT) }\end{array}$ & All candidate materials & $\begin{array}{l}\text { The MOT is determined by placing the transducer in the tube } \\
\text { furnace and increasing the temperature linearly at a slow rate so } \\
\text { that each measurement could be considered isothermal (prior } \\
\text { experience indicates that rates of } 1{ }^{\circ} \mathrm{C} / \text { minute should be used) } \\
\text { As such, the time necessary for each experiment will depend on } \\
\text { the Curie temperatures and is estimated to be on the order of } \\
500-1000 \text { minutes or } 8-16 \text { hours. } \\
\text { This test will be used to identify possible temperature induced } \\
\text { changes that may occur at the estimated irradiation temperature, } \\
\text { effects of temperature transients, and MOT. }\end{array}$ \\
\hline $\begin{array}{c}\text { Saturation } \\
\text { magnetostriction }\end{array}$ & $\begin{array}{l}\text { All magnetostrictive } \\
\text { candidate materials }\end{array}$ & $\begin{array}{l}\text { This test involves measurement of magnetostriction of candidate } \\
\text { materials as a function of applied DC magnetic field using a DC } \\
\text { current supply and a pushrod dilatometer. } \\
\text { This test will allow characterization of the performance of } \\
\text { candidate magnetostrictive materials. }\end{array}$ \\
\hline $\begin{array}{l}\text { Hysteresis } \\
\text { measurement } \\
\text { (HM) }\end{array}$ & All candidate materials & $\begin{array}{l}\text { The HM characterizes remnant polarization and indicates } \\
\text { changes in material structure. This test can be performed with } \\
\text { the transducer in situ and will be completed alongside the MOT } \\
\text { and ET. }\end{array}$ \\
\hline
\end{tabular}

\subsubsection{Out of Pile Test Results}

\subsubsection{Performance Check Out Tests}

High temperature testing was performed at PSU on each of the constructed piezoelectric transducers to ensure that these transducers will operate at the estimated peak irradiation temperature of $450{ }^{\circ} \mathrm{C}$. A data acquisition and transducer control system was used to pulse the transducers and record received data. The test setup is shown in Figure 2-19.

High temperature testing was also performed at INL on each of the constructed magnetostrictive transducers to ensure that they operated at estimated peak irradiation temperature of $450^{\circ} \mathrm{C}$. A PC mounted Matec 


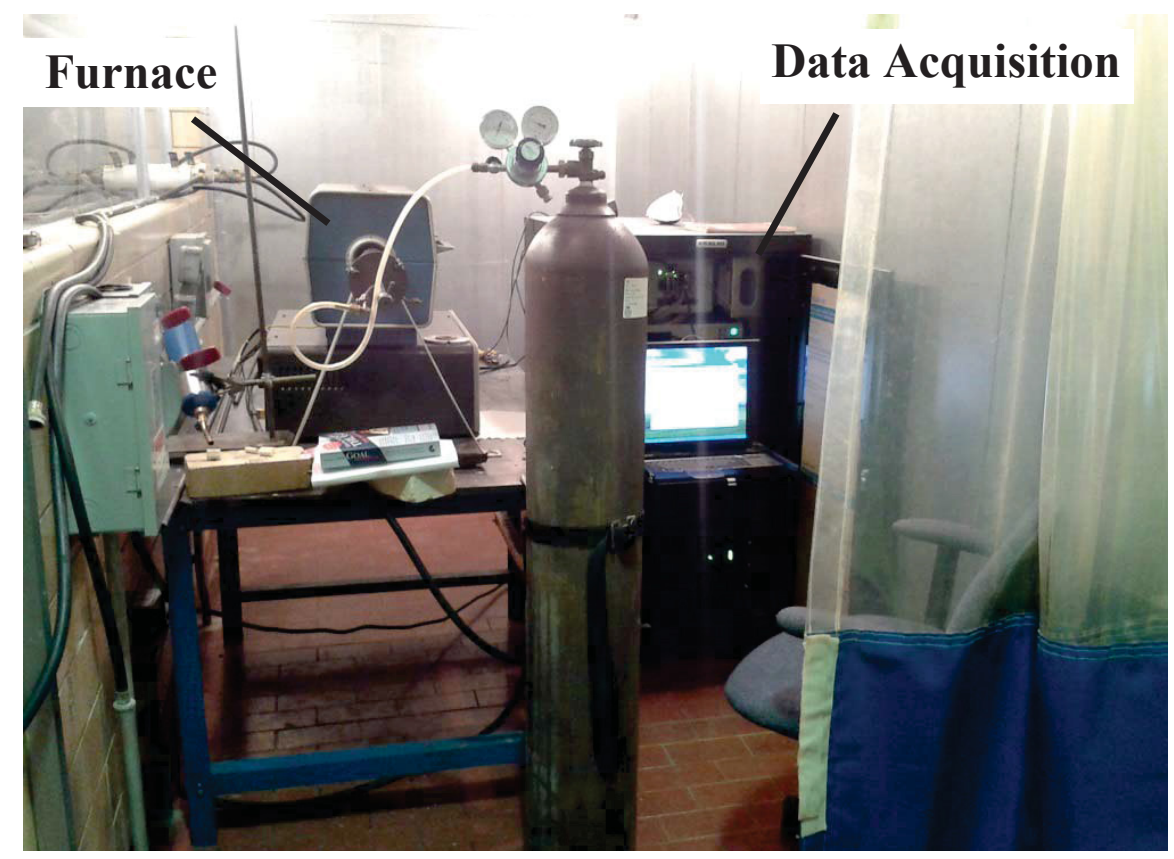

Figure 2-19. Test setup for initial piezoelectric transducer checkout.

pulser/reciever card was used to supply the input tone burst signal. A PC mounted data acquisition system from Okos Solutions was used to record received data. The test setup is shown in Figure 2-20.

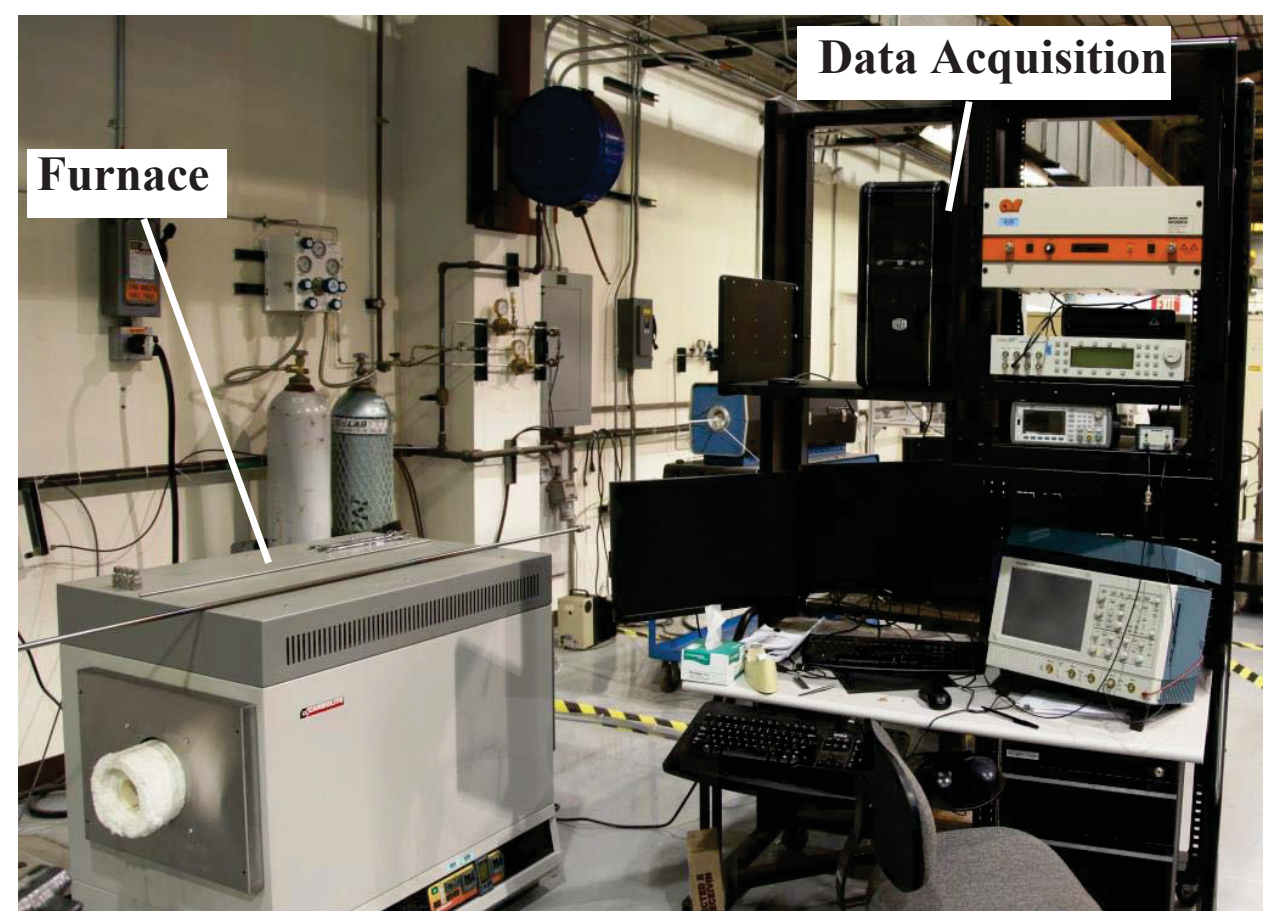

Figure 2-20. Setup used for initial magnetostrictive transducer checkout. 


\subsubsection{Out of Pile Characterization Tests}

Out of pile characterization tests, needed for separating temperature effects from irradiation effects, have been initiated by PSU. Results will be included in the final report for this effort.

\subsection{Summary}

As described in this section, this project is supporting an ultrasonic transducer irradiation test that will be performed in the MITR. During FY-2013, funding was used to define irradiation test conditions and test locations. Candidate piezoelectric and magnetostrictive transducers were designed and fabricated. A previously designed test capsule was redesigned due to predicted test temperatures above the limitations of some components. A series of out-of pile tests, which will help distinguish the effects of non-radiation factors, such as temperature, and characterize the pre-irradiation performance of each candidate, was begun. 


\section{TASK 2: ULTRASONIC SIGNAL PROCESSING METHODS}

\subsection{Summary of Work to Date}

FY-2012 work on Task 2 was limited to an extensive background review of the various desired measurement parameters, how those parameters could be measured using ultrasonics, and what signal characteristics could be used to infer the desired information. A strategy for incorporating the different required signal processing methodologies was also developed. Due to higher priority needs to support the irradiation test capsule installation in early FY-2014, work on the signal processing enhancements was deferred until FY-2014.

\subsection{Strategy for FY-2014}

FY-2014 work will focus on development and demonstration of signal processing method enhancements for ultrasonic thermometry applications. This will include measurements using multiple segment waveguide type ultrasonic thermometers based on magnetostrictive or piezoelectric transducers similar in design to those being evaluated in the transducer irradiation test of Task 1. As a first step, INL will provide data for development and demonstration of candidate signal processing method enhancements that will be performed by PNNL and ANL. In addition, data from the PSU-led MITR irradiation test, and PSU-performed elevated temperature tests of magnetostrictive and piezoelectric transducers will be used to assess the effects of irradiation and temperature on transducers and waveguides and the enhancements offered by possible compensation methods. Identification of gaps in the developed methodology and proposed follow-on work to address these gaps will be documented by PNNL, ANL, and INL. A flow chart describing the FY-2014 work process is shown in Figure 3-1.

\section{Data Synthesis}

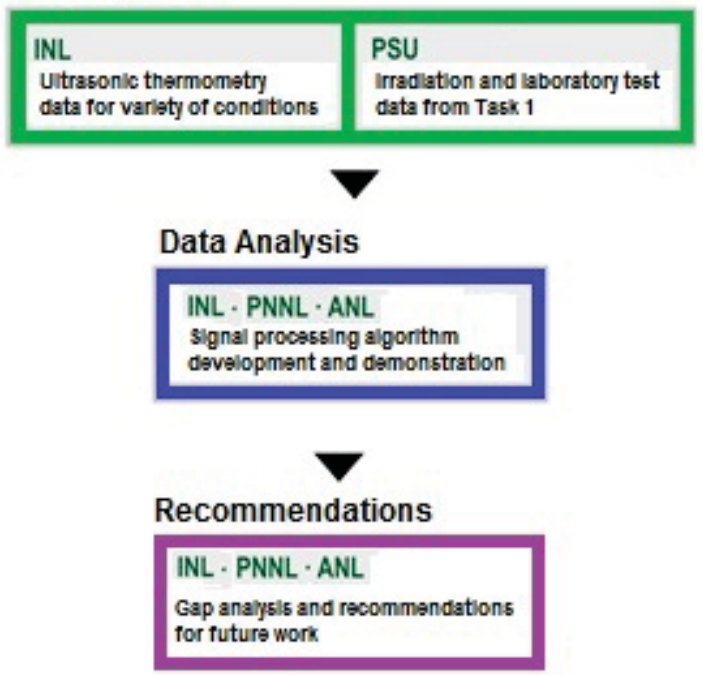

Figure 3-1. Signal processing enhancement project flow chart. 
NEET In-Pile Ultrasonic Sensor Enablement-FY 2013 Status Report

September 2013 


\section{SUMMARY}

As discussed within this document, all planned FY-2013 efforts were completed (although Task 1 efforts were accelerated to accommodated the schedule of the PSU-led ultrasound transducer irradiation test funded by the ATR NSUF program, and Task 2 efforts were deferred to FY-2014). Highlights of the FY-2013 accomplishments are summarized within this section.

\subsection{Irradiation Test}

Task 1 of this project supports efforts to develop a test capsule design and define irradiation conditions for evaluating most promising candidate piezoelectric and magnetostrictive transducer materials and designs. This test capsule will be irradiated in the MIT test reactor for approximately 310 full power days, accumulating a total fluence of greater than $1 \times 10^{21} \mathrm{n} / \mathrm{cm}^{2}$.

The proposed testing conditions are:

- Temperature: $350{ }^{\circ} \mathrm{C}-450{ }^{\circ} \mathrm{C}$,

- Fast Flux (>1 MeV): $3.5 \times 10^{13} \mathrm{n} / \mathrm{cm}^{2} * \mathrm{sec}$,

- Gas Environment: Helium (possibly including a small amount of neon for temperature control)

The proposed test capsule is a cylindrical graphite sample holder designed to accommodate four piezoelectric and two magnetostrictive transducers (see Figure 4-1, repeated from Section 2.1.2). The capsule will also hold instrumentation to monitor capsule temperature, fast and thermal flux, and gamma heating.
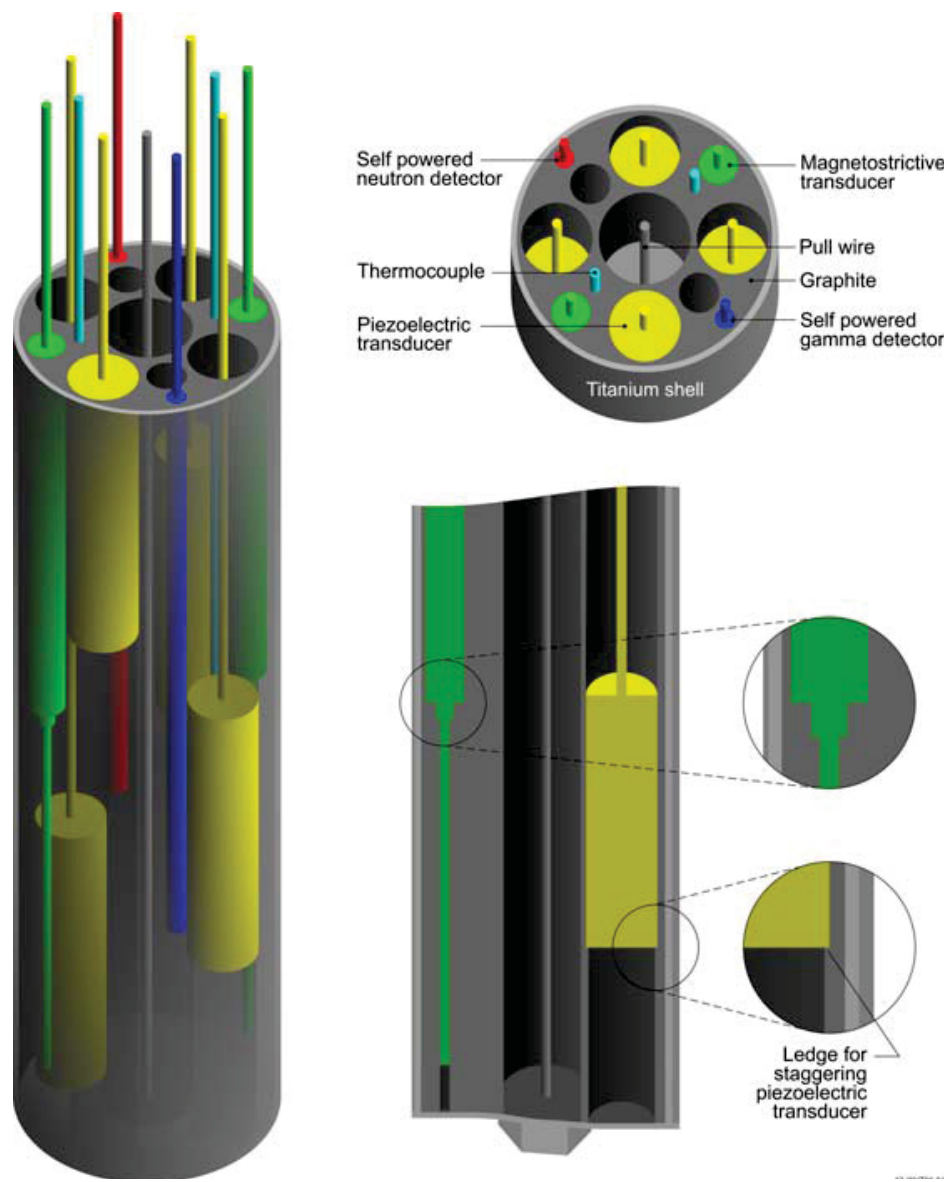

Figure 4-1. Final test capsule graphite sample holder design with sample and instrumentation positions detailed. 
Four piezoelectric transducers will be included in the irradiation test. The transducers will use three different piezoelectric materials (aluminum nitride, zinc oxide and bismuth titanate) for transduction. Zinc oxide will be used in two of the transducers, for redundancy (as zinc oxide is considered the most interesting material). These materials were selected based on their transduction performance and anticipated resistance to radiation and high temperatures. Important properties of the selected piezoelectric materials are summarized in Table 4-1 (repeated from Section 2.2.1). In addition to the piezoelectric transducers, loose samples of each material will also be irradiated in order to facilitate easier PIE.

Table 4-1. Candidate piezoelectric materials.

\begin{tabular}{|c|c|c|c|c|}
\hline Material & Composition & $\begin{array}{c}\text { Transition } \\
\text { Temperature, }\end{array}{ }^{\circ} \mathbf{C}$ & Transition Type & Comments \\
\hline Bismuth Titanate & $\mathrm{Bi}_{4} \mathrm{Ti}_{3} \mathrm{O}_{12}$, etc. & 909 & Curie Temperature & $\begin{array}{c}\text { Thought to be radiation tolerant. Most } \\
\text { promising previously tested candidate. } \\
\text { Good baseline comparator. }\end{array}$ \\
\hline Aluminum Nitride & $\mathrm{AlN}$ & 2200 & Melt & $\begin{array}{c}\text { Thought to be highly radiation tolerant. } \\
\text { Very high temperature capability. }\end{array}$ \\
\hline Zinc Oxide & $\mathrm{ZnO}$ & $>1500$ & Melt & $\begin{array}{c}\text { Thought to be highly radiation tolerant. } \\
\text { High temperature capability. }\end{array}$ \\
\hline
\end{tabular}

Two magnetostrictive transducers will be included in the irradiation test. The transducers will use Remendur and Galfenol as the transduction materials. These materials were selected based on their transduction performance and high temperature operation as well as previous use in irradiation applications (in the case of Remendur). In addition to the transducers, loose samples of each material will also be irradiated in order to facilitate easier PIE. Two materials not included in transducers (Arnokrome 4 and Arnokrome 5) will also be included as loose samples. These materials were omitted as transducer candidates due to thermal analysis predicting temperatures exceeding the limitations of the excluded materials and because the included materials were considered more promising. Important properties of the selected magnetostrictive materials are summarized in Table 4-2 (repeated from Section 2.2.3).

Table 4-2. Candidate magnetostrictive materials.

\begin{tabular}{|c|c|c|c|}
\hline Material & Composition & Key Properties & Comments \\
\hline Remendur & $49 \mathrm{Fe}-49 \mathrm{Co}-2 \mathrm{~V}$ & $\begin{array}{c}\text { 70-100 } \mu \text {-strain max. magnetostriction, } \\
\text { curie temperature } 950{ }^{\circ} \mathrm{C}\end{array}$ & $\begin{array}{l}\text { No longer manufactured, identical } / \text { similar } \\
\text { alloys available, possible activation of cobalt }\end{array}$ \\
\hline Galfenol & Fe-14Ga-NbC & $\begin{array}{c}100-400 \mu \text {-strain max. magnetostriction, } \\
\text { curie temperature } 700{ }^{\circ} \mathrm{C}\end{array}$ & $\begin{array}{l}\text { Relatively new, small amounts of data, } \\
\text { difficult to acquire }\end{array}$ \\
\hline Arnakrome 4 & $95 \mathrm{Fe}-5 \mathrm{Cr}$ & $\begin{array}{l}\text { 10-40 } \mu \text {-strain max. magnetostriction, } \\
\text { curie temperature } 770{ }^{\circ} \mathrm{C}\end{array}$ & Low magnetostriction \\
\hline Arnakrome 5 & $92 \mathrm{Fe}-8 \mathrm{Mn}$ & $\begin{array}{l}10-40 \mu \text {-strain max. magnetostriction, } \\
\text { curie temperature } 770{ }^{\circ} \mathrm{C}\end{array}$ & Low magnetostriction \\
\hline
\end{tabular}

\subsection{Signal Processing Development}

Work toward an enhanced signal processing capability was deferred to FY-2014 so that Task 1 efforts could be accelerated to support the accelerated schedule for the PSU-led transducer irradiation test funded by the ATR NSUF Program. 


\subsection{Future Work}

As noted within this document, it is anticipated that the test capsule will be inserted into the MITR in early FY-2014. Hence, FY-2014 work will focus on development of an enhanced signal processing capability for ultrasonic thermometry (selected as an ultrasound based sensor which could be deployed in the near term). FY-2014 work will also involve continuing support of the transducer irradiation test. This will consist of validating the interpretation of data from the irradiation test and the out of pile tests used to separate the effects of temperature from irradiation effects on the sensors. 
NEET In-Pile Ultrasonic Sensor Enablement-FY 2013 Status Report

September 2013 


\section{REFERENCES}

1. J. Rempe, J. Daw, R. Schley, K. Davis, T. Unruh, B. Chase, and J. Palmer, In-pile Instrumentation to Support Fuel Cycle Research and Development-FY13 Status Report, FCRD-FUEL-2013-000237 (also Issued as INL/EXT-13-29848), September 2013.

2. J. Rempe, H. MacLean, R. Schley, D. Hurley, J. Daw, S. Taylor, J. Smith, J. Svoboda, D. Kotter, D. Knudson, S. C. Wilkins, M. Guers, L. Bond, L. Ott, J. McDuffee, E. Parma, and G. Rochau, New In-Pile Instrumentation to Support Fuel Cycle Research and Development, FCRD-FUEL-2011-000033 (also issued as INL/EXT-10-19149), January 2011.

3. C. Grandy, Argonne National Laboratory, personal communication to J. Rempe, Idaho National Laboratory, July 2012.

4. K. Natesan, M. Li, S. Majumdar, R.K. Nanstad, and T.-L. Sham, "Code Qualification of Structural Materials for AFCI Advanced Recycling Reactors,” ANL-AFCI-244, September 2008.

5. Light Water Reactor Sustainability Program Integrated Program Plan, INL/EXT-11-23452, January 2012.

6. Technical Program Plan for the Next Generation Nuclear Plant/Advanced Gas Reactor Fuel Development and Qualification Program, PLN-3636, September 30, 2010.

7. Summary for the Next Generation Nuclear Plant Project In Review, INL/EXT-10-19142, Rev 1, September 2010.

8. Next Generation Nuclear Plant Project Research and Development Status, INL/EXT-10-19259, August 2010.

9. K. Natesan, S. Majumdar, P.S. Shankar, and V.N. Shah, "Preliminary Materials Selection Issues for the Next Generation Nuclear Plant Reactor Pressure Vessel,” ANL/EXT-06/45, September 2006.

10. US Department of Energy, Office of Nuclera Energy, "Nuclear Energy Enabling Technologies Office of Nuclear Energy Advanced Sensors and Instrumentation Integrated Research Plan," September 2012.

11. K. Maeda, S. Sasaki, M. Kato, Y. Kihara. J. Nucl. Mater. 389 (2009) 78.

12. P. Millet, INL, informal communication to J. Rempe, INL, June 2010.

13. N. Chauvin, A. Courcelle, M. Pelletier, Y. Guerin, JM. Escleine, M. Phelip, F. Michel, S. Bejaoui, and M. Lainet, "Fuel Design, Irradiation Programme and Modelling, Application to Several Fuels for GENIV Systems," presentation at 2010 ATR NSUF User's Week, June 2010.

14. S. Sham, ORNL, email, to J. Rempe, INL, dated August 5, 2012.

15. J. Daw, J. Rempe, P. Ramuhalli, R. Montgomery, H.T. Chien, B. Tittmann, B. Reinhardt, NEET In-Pile Ultrasonic Sensor Enablement-FY 2012 Status Report, INL/EXT-12-27233, September 2012.

16. US NRC, "Safety Evaluation Report Related to the Construction of Clinch River Breeder Reactor Plant, Nuclear Regulatory Commission, USNRC Report, NUREG-0968,vol. 1, Main Report, March 1983. 
17. D. Petti, INL, informal communication to J. Rempe, INL, July 27, 2012.

18. J.T. Busby and M.N. Gussev, "Assessment of Initial Test Conditions for Experiments to Assess Irradiation Assisted Stress Corrosion Cracking Mechanisms," ORNL/TM-2010/346, December 2010.

19. US NRC, "Safety Evaluation Report Related to the Construction of Clinch River Breeder Reactor Plant, Nuclear Regulatory Commission, USNRC Report, NUREG-0968,vol. 1, Main Report, March 1983.

20. R.K. Nanstad, "Reactor Pressure Vessel Task of Light Water Reactor Sustainability Program: Assessment of High Value Surveillance Materials," ORNL/LTR-2011/172, June 2011.

21. K. Natesan, A. Purohit, S. W. Tam, "Materials Behavior in HTGR Environments," NUREG/ CR-6824, July 2003.

22. D. Ensminger, and L. J. Bond, Ultrasonics: Fundamentals, Technologies, and Applications, CRC Press, 2012.

23. K. Phani, et. al, "Estimation of Elastic Properties of Nuclear Fuel Material Using Longitudinal Ultrasonic Velocity - A New Approach,” J. Nucl. Mat., 366, 2007, pp. 129-136.

24. J. F. Villard, et. al.,"Acoustic Sensor for In-Pile Fuel Rod Fission Gas Release Measurement," IEEE Transactions on Nuclear Science, 58, 2011, pp. 151-155.

25. L.C. Lynnworth, "Ultrasonic Measurements for Process Control: Theory, Techniques, and Applications," Academic Press, 1989.

26. MITR Users Guide Rev. 3 July 2012, Massachusetts Institute of Technology (2012).

27. N. Gopalsami, A.C. Raptis, "Acoustic Velocity and Attenuation Measurements in Thin Rods with Application to Temperature Profiling in Coal Gasification Systems," IEEE Transactions on Sonics and Ultrasonics, SU-31, 1984, pp. 32-39.

28. K. E. Holbert, S. Sankaranarayanan, S. S. McCready, "Response of Lead Metaniobate Acoustic Emission Sensors to Gamma Irradiation," IEEE Transactions on Nuclear Science, vol. 52, no. 6, 2005, pp. 2583-2590.

29. Kulikov, et al., "Computer simulation of ferroelectric property changes in PLZT ceramics under neutron irradiation," Proceedings of SPIE, 4348, 2001, pp. 264-269.

30. H. Shea, "Radiation sensitivity of microelectromechanical system devices," J. Micro/Nanolith., 8, 2009, pp. 1-11.

31. Wittels \& Sherrill, "Fast Neutron Effects in Tetragonal Barium Titanate," Journal of Applied Physics, 28 [5], 1957, pp. 606-609.

32. W. Primak, T. Anderson, "Metamimictization of Lithium Niobate by Thermal Neutrons," Nuclear Technology, 23, 1975, pp. 235.

33. T.K. Bierney, "Instrumentation for the Measurement of Vibration in Severe Environments Such as Nuclear Reactors,” Endevco Technical Paper 272, 1976, pp. 1-8. 
34. D.A. Parks, B. R. Tittmann. "Ultrasonic NDE in a Reactor Core," Presented at Review of Progress in Quantitative Nondestructive Evaluation, July 17-22, Burlington, VT, 2011.

35. R. Kazys, V. Voleisis, R. Sliteris, B. Voleisiene, L. Mazeika, and H. Abderrahim, "Research and Development of Radiation Resistant Ultrasonic Sensors for Quasi-Image Forming Systems in a Liquid Lead-Bismuth," Ultragarsas (Ultrasound), 62(3),2006, pp. 7-15.

36. N. D. Patel, and P. S. Nicholson, "High Frequency - High Temperature Ultrasonic Transducers," NDT International, pp. 262-266, 1990.

37. D. Stubbs, and R. Dutton, "High-Temperature Ultrasonic Sensor for in Situ Monitoring of Hot Isostatic Processing," SPIE, 1996, pp. 164-172

38. K. Trachenko, "Understanding resistance to amorphization by radiation damage," Journal of Physics: Condensed Matter, 16(49), 2004, pp. R1491-R1515.

39. T. Yano, K. Inokuchi, M. Shikama, and J. Ukai, "Neutron irradiation effects on isotope tailored aluminum nitride ceramics by a fast reactor up to $2 \cdot 10^{26} \mathrm{n} / \mathrm{m}^{2}$," Journal of Nuclear Materials, 2004, pp. $1471-1475$.

40. Y. Ito, et al., "Radiation Damage of Materials Due to High Energy Ion Irradiation," Nuclear Instruments and Methods in Physics Research, 530, 2002

41. Y. P. Meleshko, S. G. Karpechko, G. K. Leont'ev, V. I. Nalivaev, A. D. Nikiforov, and V. M., "Radiation Resistance of the Piezoelectric Ceramics TrsTS-21 and TNV-I," Translated from Atomnaya Energiya, 1986, pp. 50-52.

42. L.C. Lynnworth, E.H. Carnevale, M.S. McDonough, S.S. Fam, "Ultrasonic Thermometry for Nuclear Reactors," IEEE Transactions on Nuclear Science, Vol. NS-16, pp. 184-187, 1968.

43. L.C. Lynnworth, "Nuclear Reactor Thermometry," US Patent Application 3,597,316: 3 Aug 1971.

44. S.C. Rogers, G.N. Miller, "Ultrasonic Level, Temperature, and Density Sensor," IEEE Trans. on Nuclear Science, 29 (1), 1982, pp. 665-668.

45. J. Daw, J. Rempe, S. Taylor, J. Crepeau, and S.C. Wilkins., "Ultrasonic Thermometry for In-Pile Temperature Detection," Proceedings of NPIC\&HMIT 2010, 2010.

46. "What is Galfenol?", Etrema Products, Inc., http:/www.etrema-usa.com/core/galfenol/, Accessed 08/ $09 / 2012$.

47. Arnokrome 3 Datasheet Rev. 01-11-11,www.arnoldmagnetics.com/WorkArea/DownloadAsset.aspx?id=5262, Accessed 08/09/2012.

48. Arnokrome 4 Specification Rev. 1/11/11,www.arnoldmagnetics.com/WorkArea/DownloadAsset.aspx?id=5263, Accessed 08/09/2012.

49. Arnokrome 5 Specification Rev. 2/24/11,www.arnoldmagnetics.com/WorkArea/DownloadAsset.aspx?id=5328, Accessed 08/09/2012.

50. R.S. Sery, et al., "Radiation Damage Thresholds for Permanent Magnets," NOLTR 61-45, 1961. 
51. Liu, et al., "Thermal Stability and Radiation Resistance of Sm-Co Based Permanent Magnets," Paper 2036, Proceedings of Space Nuclear Conference, 2007.

52. Thermocoax http://www.thermocoax.com/doc-Signal_Transmission/E004-3-STC-low-capacitace-SIO2.pdf 